\title{
1 Run-out of landslides in brittle soils
}

2 A. Yerro $^{1}$ \& E.E. Alonso ${ }^{1,2}$ \& N.M. Pinyol ${ }^{1,2}$

$3 \quad{ }^{1}$ Department of Geotechnical Engineering and Geosciences, UPC, Barcelona, Spain

$4 \quad{ }^{2}$ Centre Internacional de Mètodes Numèrics en Enginyeria

6 ABSTRACT: One of the factors causing the acceleration of landslides is the loss of strength of 7 the soil involved in the potential unstable mechanism. The travelled distance and the landslide 8 velocity, a key factor in risk analysis, will be determined by the loss of resistant forces. Brittle 9 behaviour, commonly associated with cemented soils, overconsolidated plastic clay formations and sensitive clays, lead to the progressive failure phenomenon explained by the reduction of the strength with increasing strain. In the present study, this phenomenon has been analysed in the case of a saturated slope which becomes unstable by increasing the boundary pore water pressure. A Mohr-Coulomb model with strain softening behaviour induced by increasing deviatoric plastic strain is used. The paper focusses not only on the stability of the slope but also on the post failure behaviour (run-out and sliding velocity). A coupled hydro-mechanical formulation of the Material Point Method has been used to simulate the whole instability process. The influence of the brittleness of the material on the triggering of instability and runout is evaluated by means of a parametric study varying peak and residual strength. The onset of the failure and the failure geometry are controlled by both peak and residual values. Good correlations between run-outs and brittleness are found. The decay of the strength determines the acceleration of the landslides and the travelled distance.

\section{INTRODUCTION}

The dynamic behaviour of landslides receives increasing attention because landslide risk analysis and spatial identification of vulnerable areas require estimations of the slide run-out and the velocity of the unstable mass [1]. Special attention is given to reservoirs, lakes and fjords potentially affected by landslides on their margins [2-4]. In fact, slope instabilities may affect dams and their foundations and they may lead to partial or complete blockage of rivers, creating dangerous "natural" dams or the generation of a destructive wave due to the impact of the landslide against the stored water [5-7]. The potential damage caused by landslides can be determined by several factors related with the volume of the mobilized mass, the run-out, velocity and acceleration. One of the factors that control the acceleration of the slide is the loss of resistant forces associated with the drop of available soil strength. This phenomenon is typically observed in first time failure developed in "intact" sites in materials exhibiting a brittle behaviour. This is the case of hard soils and soft rocks, overconsolidated and cemented clayey 
soils with special relevance in the case of high plasticity soils. These materials exhibit a softening behaviour from a peak value, associated with a low value of shearing displacements, to a low residual strength when bonds are destroyed and clay particles orient in the direction of shearing. This reduction of strength leads to the propagation of the failure surface following a process of progressive failure.

When a point exceeds the maximum available strength, a degradation process initiates due to the strain softening associated with the constitutive response of the material. The unbalanced stresses are transferred to the surrounding areas which in turn may overstress neighbouring points in the process, leading eventually to residual strength conditions. This stress transfer phenomenon develops during slip surface propagation. This mechanism was first recognized by Terzaghi and Peck [8] and Taylor [9]. It was further discussed in the context of overconsolidated clays and clay shales by Skempton [10], Bjerrum [11] and Bishop [12]. Further contribution are made by Palmer and Rice [13], Stark and Eid [14], and Puzrin and Germanovich [15].

Several real cases involving progressive failure are collected and analyzed in the literature [1620]. Troncone [21] presents a 2D numerical analysis of well documented Senise large landslides in Southern Italy and a 3D extension in [22]. Other real cases of landslides involving progressive failure mechanism in the Iberian Peninsula have been collected in [23].

Contributions mentioned above mainly concentrate on the analysis of the generation and evolution of the failure surface but the run-out stage, once instability occurs, is not explored. Modelling large displacement involves the use of alternative calculation techniques to the Lagranian approaches generally used in FEM. Soga et al. [24] reviews current numerical methods capable of analysing the slide motion. In this work, the Material Point Method (MPM) [25] is selected to analyse the stability of slopes and their post failure response in strain softening materials. MPM is a numerical technique able to simulate large displacements by means of combining two discretizations of the media: (a) a set of material points which move through (b) a fixed computational grid. This dual description prevents mesh distortion problems and contacts between different bodies are automatically solved.

A fully coupled hydro-mechanical material point code was developed for saturated soils within the MPM Research Community framework [26-29]. A strain softening elastoplastic constitutive law was has been implemented with the purpose of analysing progressive failure phenomena that take place in materials exhibiting a reduction of the strength with increasing strain [30].

This MPM formulation was recently applied in Alonso et al. [31] to model the Selborne failure experiment [32]. Failure of the Selborne slope was triggered by forced water recharge. Field 
instrumentation data indicated that the failure was a progressive mechanism in overconsolidated brittle clays. The numerical MPM analysis presented in [31] provided consistent and accurate results in the prediction of the shape and position of the failure surface, the development of progressive failure and the slide motion after failure.

The aim of the paper is to explore the response of saturated slopes in brittle materials. It focusses on exploring the material properties controlling the run-out distance and velocity of the unstable mass in brittle materials. First, a synthetic slope is presented in which the shear stress distribution and the progression of failure mechanism are discussed. Afterwards, by means a parametric analysis, the brittle behaviour of the material soil (defined in terms of brittleness index $I_{B}$ ) is shown to be a key factor of the slope response. The results are discussed with the aim of deriving practical conclusions.

\section{BASIS OF MPM FORMULATION}

The MPM [33] discretizes the continuum as a set of subdomains. In the standard approach, presented by Sulsky et al. [25], the mass of each subdomain is considered to be concentrated in a point, the material point (Fig. 1). Other properties such as velocities, strains and stresses, are also carried by the material points. This information is projected on to a background mesh where governing equation are solved. The support computational mesh covers the full domain of the problem and remains fixed during calculation. Calculations on the mesh serve to update the material point properties and location. Linear interpolation shape functions are used to provide the relationship between material points and nodes at any point of the domain. This approach allows MPM to combine the advantages of Eulerian and Lagrangian formulations.

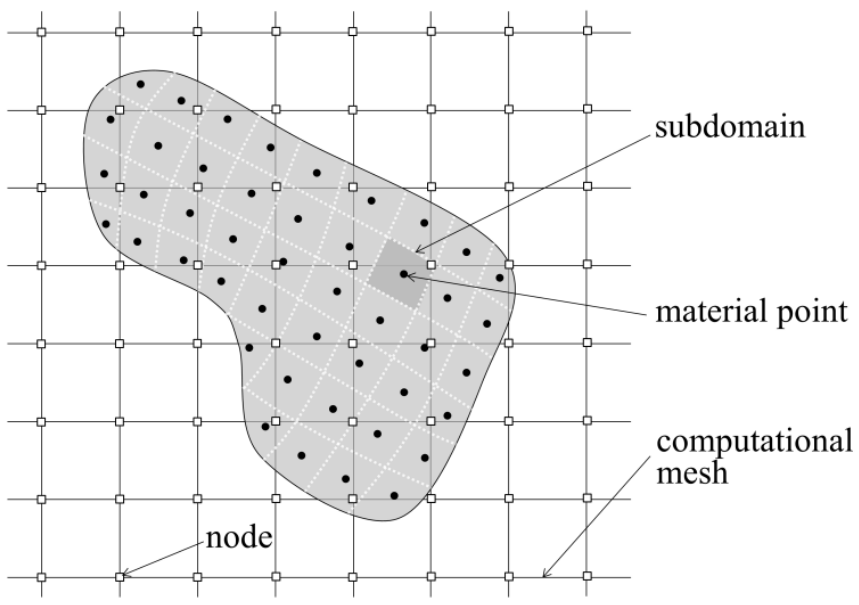

Fig. 1. Scheme of the spatial discretization used in MPM formulation. 
The MPM formulation for a mechanical problem was presented by Sulsky and Schryer [34]. Different authors have extended the MPM to solve coupled hydro-mechanical problems under saturated conditions [20,27,35]. More recently, Yerro et al. [28] extended MPM for unsaturated soils.

The numerical approach considered in this work to simulate saturated soils is based on [27]. It assumes that each material point represents a portion of the soil, moves attached to the solid skeleton and carries information of solid and liquid phases. Solid and liquid accelerations are calculated in the computational mesh solving the dynamic momentum balances of both phases. Velocities, displacements and strains are obtained in the material points; and liquid mass balance equation is established in the material points to provide liquid pressures. An explicit Euler-Cromer scheme [36] is used to update displacements and velocities from calculated accelerations.

In order to avoid non-physical vibrations, it is common to include a damping term in the balance equations. The approach adopted here was presented by Cundall [37]. It introduces a damping force proportional to the corresponding out-of-balance force (proportional factor $\alpha$ ) and opposite to the phase velocity. In dynamic problems, the proportional factor should be very small (0-5\%) in order to approximate the correct solution and avoid an overdamped system.

The standard MPM approach $[25,33]$ in which the mass of each material point is assumed to be concentrated at the corresponding material point, suffers from spurious oscillations when material points cross from one element to another one. It is caused by a jump discontinuity in the gradient of low-order shape functions that are used for the integration. In order to reduce this numerical problem, a simple technique of low computational cost is introduced in this work [38]. It arises from considering that the stress on each element is constant and corresponds to the average of the stresses of the material points located within a given cell. Other authors proposed more accurate techniques. For instance, Bardenhagen and Kober [39] proposed to distribute the mass of each material point in a certain region. This idea results in a family of methods known as Generalized Interpolation Material Point (GIMP) methods. More recently, MPM has been extended to convected particle domain interpolation methods (CPDI1 and CPDI2) which are developed to improve the tracking of material point domains [40,41].

\section{CONSTITUTIVE MODELLING}

In this paper the basic non-associated Mohr-Coulomb law is generalized to introduce strain softening plasticity with the aim of modelling a strength loss after peak strength conditions. In order to reduce the singularities of Mohr-Coulomb yield surface (edges and tip) that involve 
125 some numerical problems during the elasto-plastic integration, the modifications proposed by

126 Abbo and Sloan [42] have been implemented.

127 Following previous contributions [43-47], the softening behaviour is accounted for by reducing 128 the strength parameters (friction angle $\varphi^{\prime}$, and cohesion $c^{\prime}$ ) exponentially with the accumulated 129 deviatoric plastic strain $\varepsilon_{d}^{p}$ according to the following softening rules:

$130 \quad c^{\prime}=c_{r}^{\prime}+\left(c_{p}^{\prime}-c_{r}^{\prime}\right) e^{-\eta \varepsilon_{d}^{p}}$

$131 \phi^{\prime}=\phi_{r}^{\prime}+\left(\phi_{p}^{\prime}-\phi_{r}^{\prime}\right) e^{-\eta \varepsilon_{d}^{p}}$

133 The deviatoric plastic strain invariant is defined as:

$134 \quad \varepsilon_{d}^{p}=\sqrt{\frac{2}{3} \mathbf{e}_{i j}^{p} \mathbf{e}_{i j}^{p}}$

135 where $\mathbf{e}_{i j}^{p}$ is the deviatoric part of the plastic strain tensor.

136 The model requires the specification of peak $\left(c_{p}{ }^{\prime}, \varphi_{p}{ }^{\prime}\right)$ and residual $\left(c_{r}{ }^{\prime}, \varphi_{r}{ }^{\prime}\right)$ effective strength 137 parameters. An additional parameter $\eta$, a shape factor parameter, is also necessary in order to 138 control the rate of strength decrease.

139 The effect of $\eta$ in a simple shear test simulation is shown in Fig. 2. The soil parameters of the 140 material considered in these simulations are summarised in Table 1 . A vertical stress of $50 \mathrm{kPa}$ 141 and a horizontal one of $25 \mathrm{kPa}$ are applied to confine the sample. Then, a prescribed velocity is 142 imposed at the upper boundary maintaining the bottom fixed. High values of $\eta$ lead to faster 143 degradation of the soil strength. 


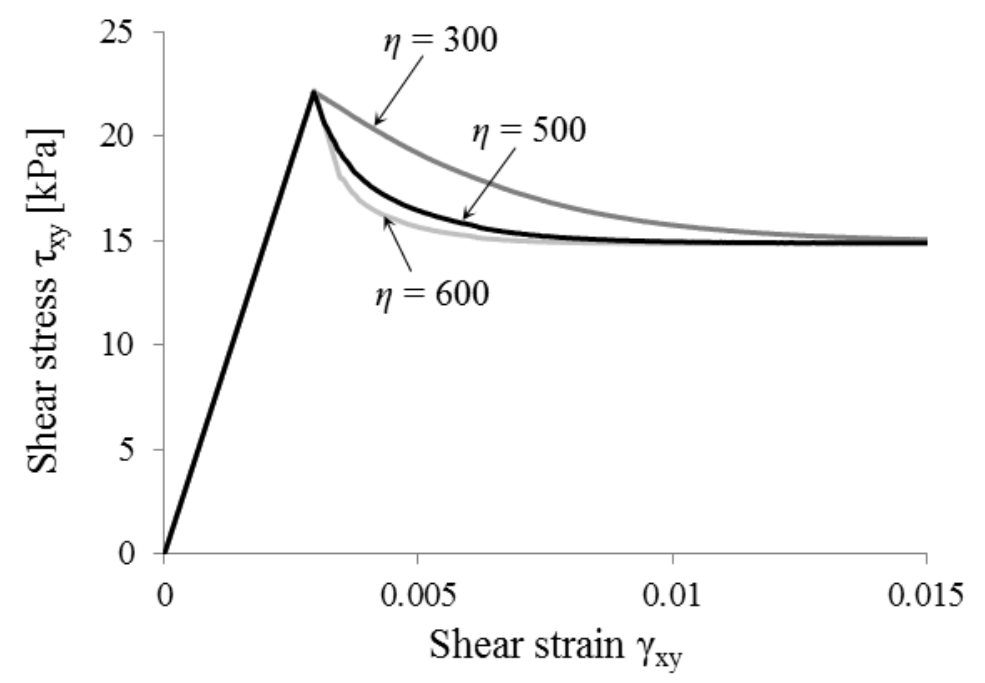

Fig. 2. Evolution of shear stress in a numerical model of a simple shear tests for different values of parameter $\eta$.

\section{A REFERENCE SLOPE INSTABILITY PROBLEM}

The instability of a synthetic slope, $6 \mathrm{~m}$ high and $37^{\circ}$ steep, was analysed (Fig. 3). The slope failure was triggered by increasing the pore water pressure at the lower boundary simulating a phreatic level rise. This is a plane strain simulation in which the boundary conditions on the vertical contours are rollers and the base is fixed. The water pressure is zero along the slope surface, the lateral contours are impermeable and saturated conditions are considered during the calculation. The mesh was refined in the region where the failure is expected in order to get more accurate results and to optimise the computational cost.

Initially the slope remains in equilibrium. The calculation starts with the application of a $40 \mathrm{kPa}$ increase in pore pressure $(\Delta P)$ along the lower boundary during 1 second. Afterwards the water pressure on the boundary is maintained constant during the entire simulation.

The Mohr-Coulomb strain softening model described in the previous section was used to simulate the brittle behaviour of a soil. The properties of the slope material are given in Table 1. The particular values selected are not relevant for the discussion presented here. The only requirement to select such values has been to ensure that the failure occurs for the imposed increment of pore water pressure. The effect of the shape factor parameter on the drop of the strength is shown in Fig. 2. 


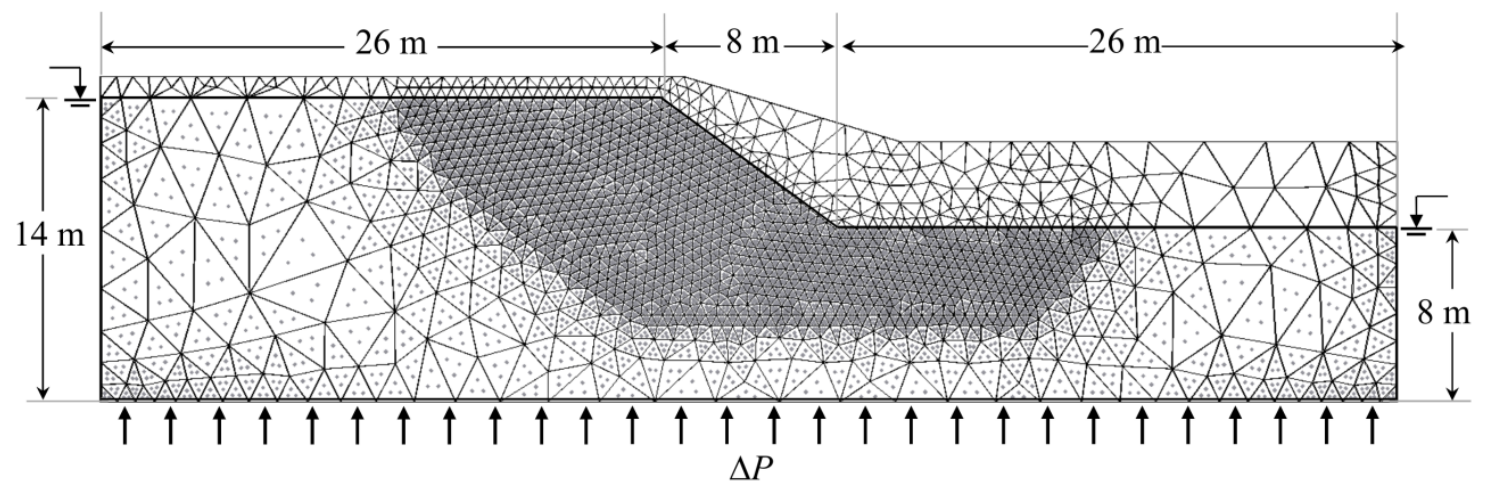

166

Fig. 3. Scheme of the MPM model. Initial distribution of the material points and computational mesh.

Table 1. Soil parameters of the slope.

\begin{tabular}{ll}
\hline Soil parameters & Value \\
\hline Porosity [-] & 0.2 \\
Intrinsic permeability [m $\left.{ }^{2}\right]$ & $10^{-10}$ \\
Young's modulus [kPa] & 20000 \\
Poisson's ratio [-] & 0.33 \\
Peak cohesion [kPa] & 5 \\
Residual cohesion [kPa] & 0.5 \\
Peak friction angle $\left[{ }^{\circ}\right]$ & 35 \\
Residual friction angle $\left[{ }^{\circ}\right]$ & 20 \\
Shape factor parameter & 500 \\
Dilatancy angle $\left[{ }^{\circ}\right]$ & 0 \\
\hline
\end{tabular}

An explicit Euler-Cromer scheme is used to discretise the governing equations. Because it is conditionally stable, very small time steps are required in the calculation. Since permeability is not a relevant parameter in the analysis presented here, a high value $(0.001 \mathrm{~m} / \mathrm{s})$ has been adopted to simulate the slope failure in a relatively short time.

In order to reduce numerical instabilities a damping force has been included in the momentum balance equation. It is proportional to the corresponding unbalanced force by means a proportional factor $\alpha=0.05$.

The increase of pore pressure reduces the effective stresses in the slope leading some points to reaching peak conditions. The strain softening effect decreases progressively the strength parameters of the plastic zones down to the residual yield surface. As a result, the gravitational stresses are sufficient to induce a progressive failure in the case analysed.

Failure development is illustrated in Fig. 4 by representing the shear strain contours at two different times. At $8.3 \mathrm{~s}$ a shear band localises providing a failure mechanism and afterwards the instability initiates. During the movement, the shear band spreads. Finally, when the new geometry becomes stable, a wider shear zone is observed (Fig. 4b). Fig. 5 shows the final 
187

188

189

190

191

192

193

194

195

196

$$
t=8.3 \mathrm{~s}
$$
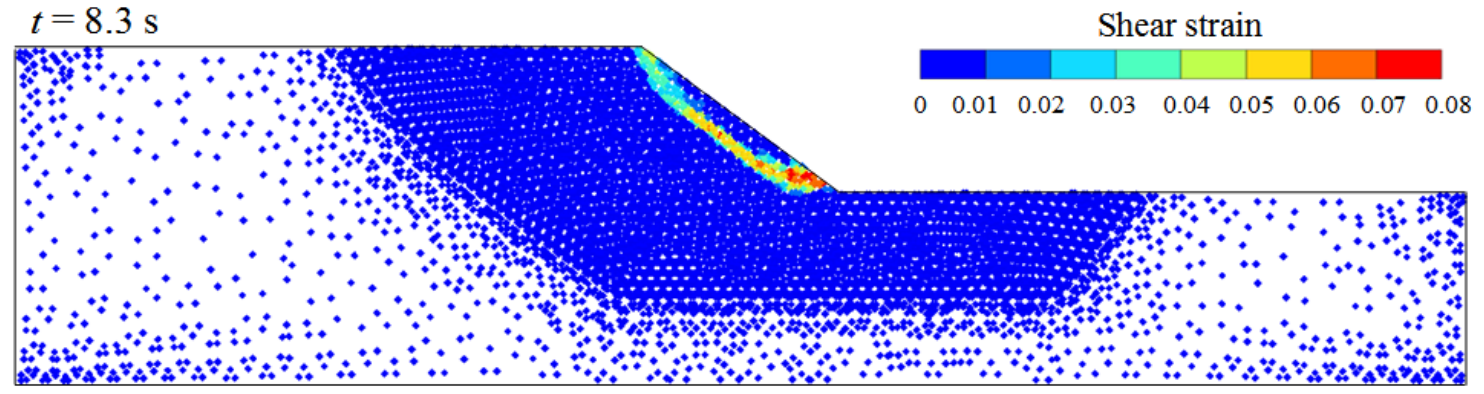

(a)

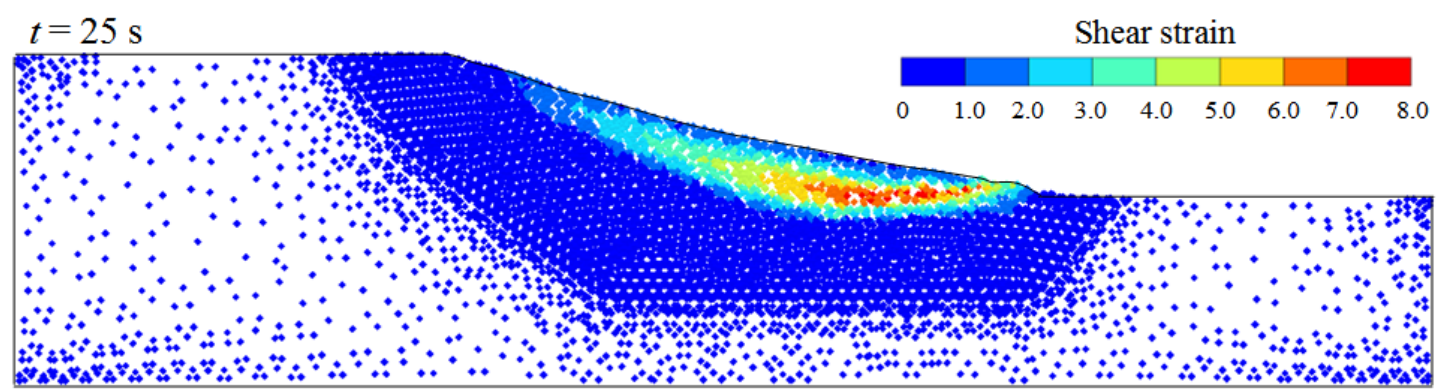

(b)

Fig. 4. Distribution of the shear strain at different times. Note the different scales of the shear strain.

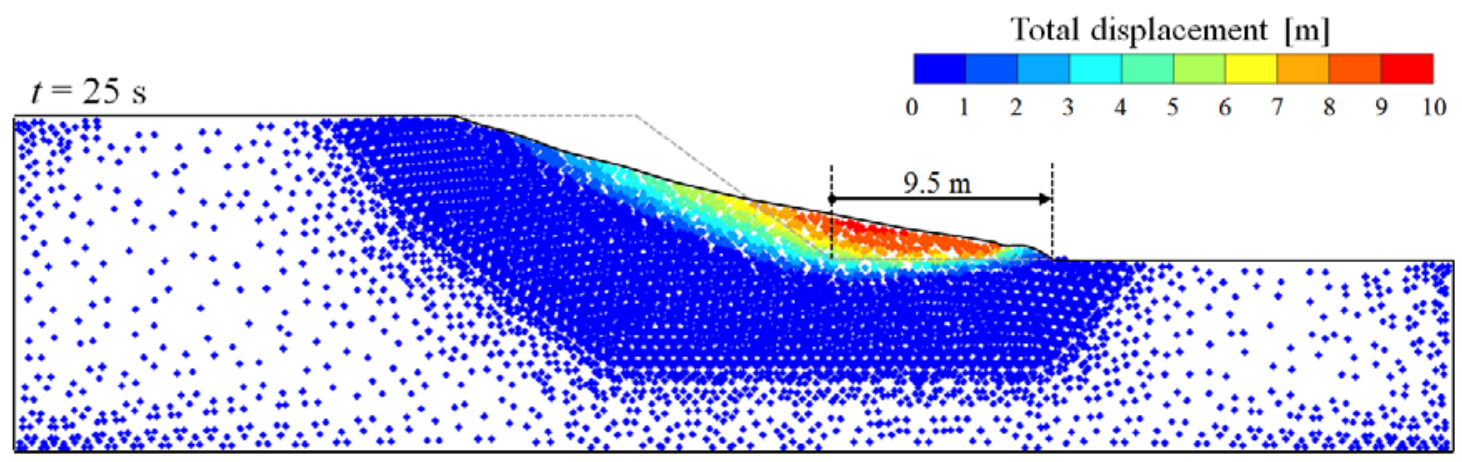

Fig. 5. Distribution of the calculated total displacement at $25 \mathrm{~s}$ after the initiation of the failure. The maximum displacement of the toe is also indicated.

Following Skempton [10], a mobilised friction angle (MFA) $\hat{\varphi}^{\prime}$ is defined as

$$
\sin \hat{\varphi}^{\prime}=\frac{q}{p+\left(c^{\prime} / \tan \varphi^{\prime}\right)}
$$

Where $q$ and $p$ ' are the deviatoric and effective volumetric stress components defined as follows:

$$
q=\frac{\sigma_{1}^{\prime}-\sigma_{3}^{\prime}}{2} \quad ; \quad p^{\prime}=\frac{\sigma_{1}^{\prime}+\sigma_{3}^{\prime}}{2}
$$

This measure of the mobilised strength is used to analyse the stress evolution of points 
homogeneously distributed along the initial failure surface. Note that $\hat{\varphi}^{\prime}$ coincides with the peak or residual friction angle values $\left(\varphi_{p}{ }^{\prime}, \varphi_{r}{ }^{\prime}\right)$ when the stress state of such a point is on the peak or residual yield surface envelopes respectively.

204 A similar analysis of the progressive failure mechanism presented in [31,50] has been carried 205 out. In Fig. 6a the progressive failure phenomenon is represented by plotting the evolution of the MFA (Eq. 5) in 7 material points located along the shear band. It indicates that the degradation of the material initiates at the foot of the slope and propagates upwards.

According to Fig. 6a, it is clear that points along the failure surface reach the peak yield envelope at different moments depending on the evolution of the progressive failure mechanism. Note that time is controlled by the evolution of pore pressures because the internal mechanical transfer of stresses in the slope is an instantaneous process.

In Fig. 6b, the evolution of the progressive failure is represented in terms of the mean mobilised friction angle. It is obtained by averaging the MFA of 20 material points distributed along the initial shear band and it is a measure of the mean mobilised strength in the failure surface. A very similar behaviour was observed in modelling of the Selborne experiment in [31]. Due to the increase of water pressure in the slope induced by the pressure condition imposed along the bottom boundary (see Fig. 3), the mean MFA increases up to a maximum value. Afterwards, there is a drop of the available mobilised strength. Then, the progressive failure develops, maintaining the mean mobilised friction angle approximately constant. This process ends abruptly at $\mathrm{t}=8.6 \mathrm{~s}$, when the final point in the failure mechanism reaches the peak condition and immediately afterwards it softens down to the residual state. This leads to the onset of instability and the motion begins.

The maximum average mobilized friction angle is attained at $t=8.25 \mathrm{~s}$, when the lower part of the failure surface has already entered into a post-peak strength. This maximum is intermediate between peak and residual strengths and, in the case analyzed, close to the residual value. If a Limit Equilibrium method is used to analyze the slope stability, the maximum calculated at $\mathrm{t}=$ $8.25 \mathrm{~s}$ is reasonable choice for the soil strength.

Beyond the maximum the average friction decreases somewhat but the process of progressive failure develops at a fairly constant value of the average friction. When the last point in the failure surface reaches peak conditions there is a sudden reduction in average friction and the slope accelerates. This is indicated in Figures $6 \mathrm{~b}$ and $7 \mathrm{a}$ as the "outset of instability". Up to this time slope displacements are small and unnoticeable at the displacement scale selected to plot Figure 7a. 
235 The behaviour of a material point (P5) is analysed in Fig. 7. Fig. 7a presents the time evolution

236 of the effective cohesion and the displacement experienced by point P5. Fig. 7b shows the stress

237 path of P5. Initially, stress conditions are given by point A in Fig. 7b. The slope remains stable.

238 Due to the increase of pore pressure imposed at the bottom boundary, the effective mean stress

239 clearly decreases. The calculated slight increase of the deviatoric stress is a consequence of the

240 stress redistribution during the initiation of the progressive failure at the toe of the slope. At 8.2

$241 \mathrm{~s}$ (indicated by point B in Fig. 7b), this particular material point reaches the peak yield surface.

242 The material point plastifies, triggering a sudden drop of the cohesion (controlled by $\eta$ ), from

243 peak to residual value. At $\mathrm{t}=8.6 \mathrm{~s}$ (the time required to develop the global failure mechanism)

244 the slope becomes unstable and it accelerates. During the instability process, the stresses remain

245 on the residual yield surface despite some numerical oscillations. At $t=15 \mathrm{~s}$, after $5 \mathrm{~m}$ of

246 displacement, the material point stops when equilibrium has been established for the final

247 geometry. Beyond $\mathrm{t}=15 \mathrm{~s}$ the stress stated of point P5 unloads slightly and enters into the elastic

248 domain.

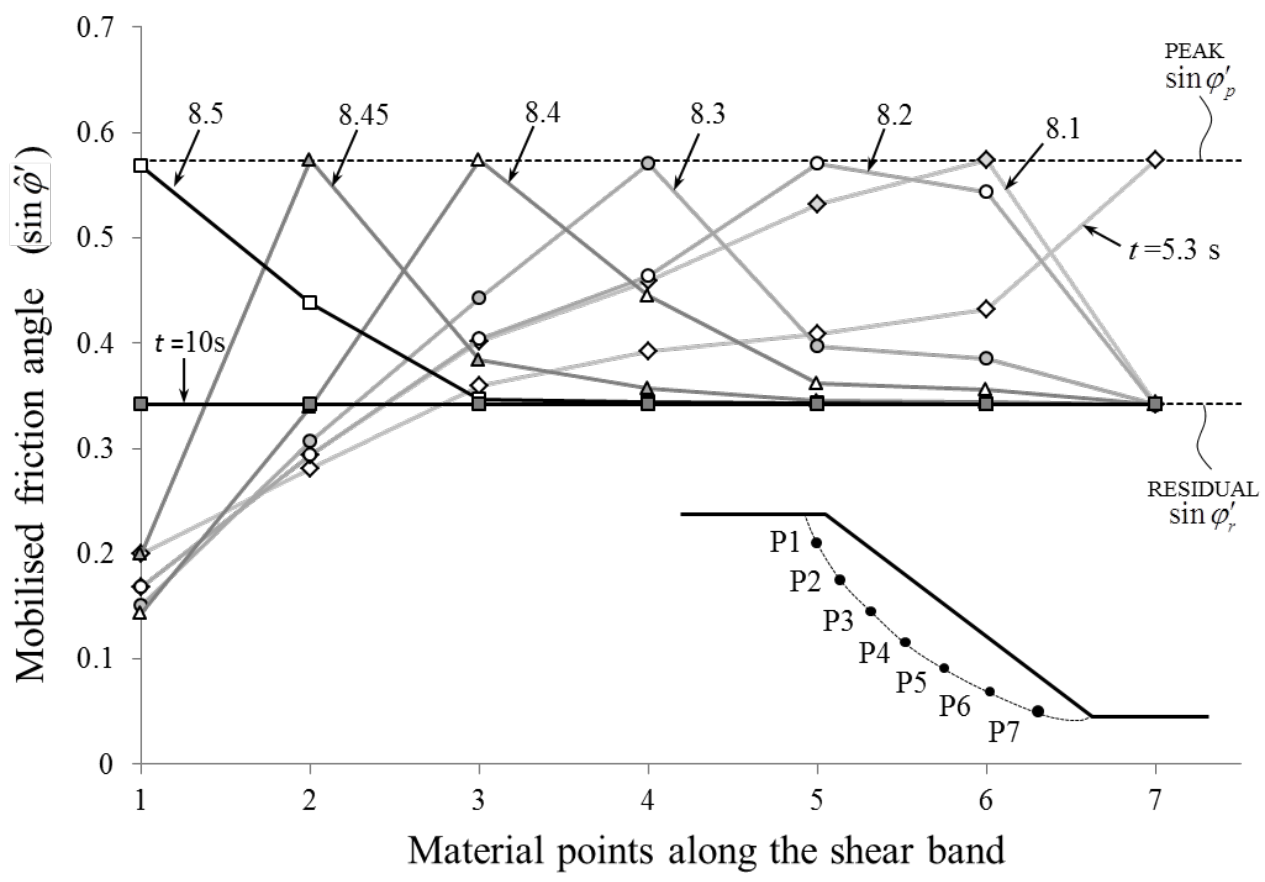




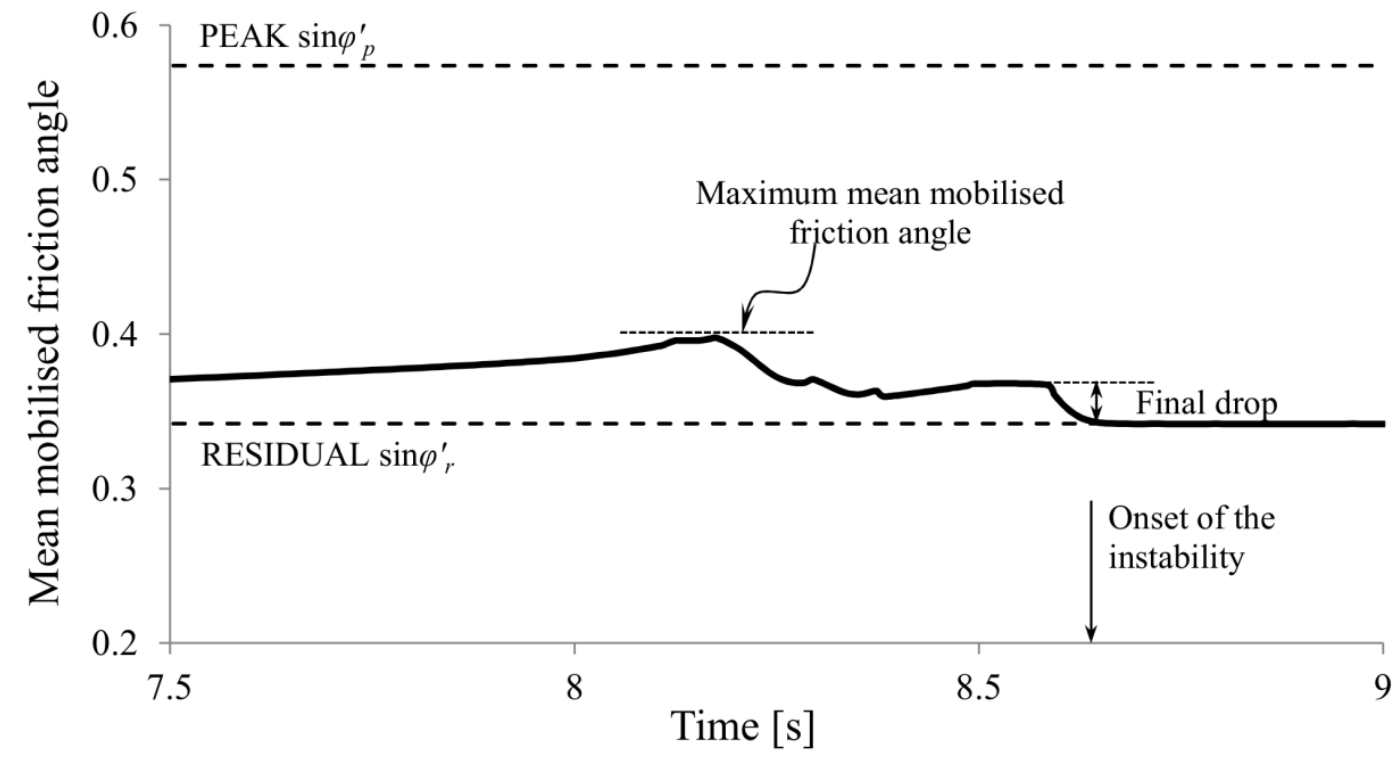

251

252

253

254

255

256

257 (b)

Fig. 6. (a) Distribution of the mobilised friction angle along the initial shear band at different times. (b) Evolution of progressive failure in terms of mean mobilised friction angle.

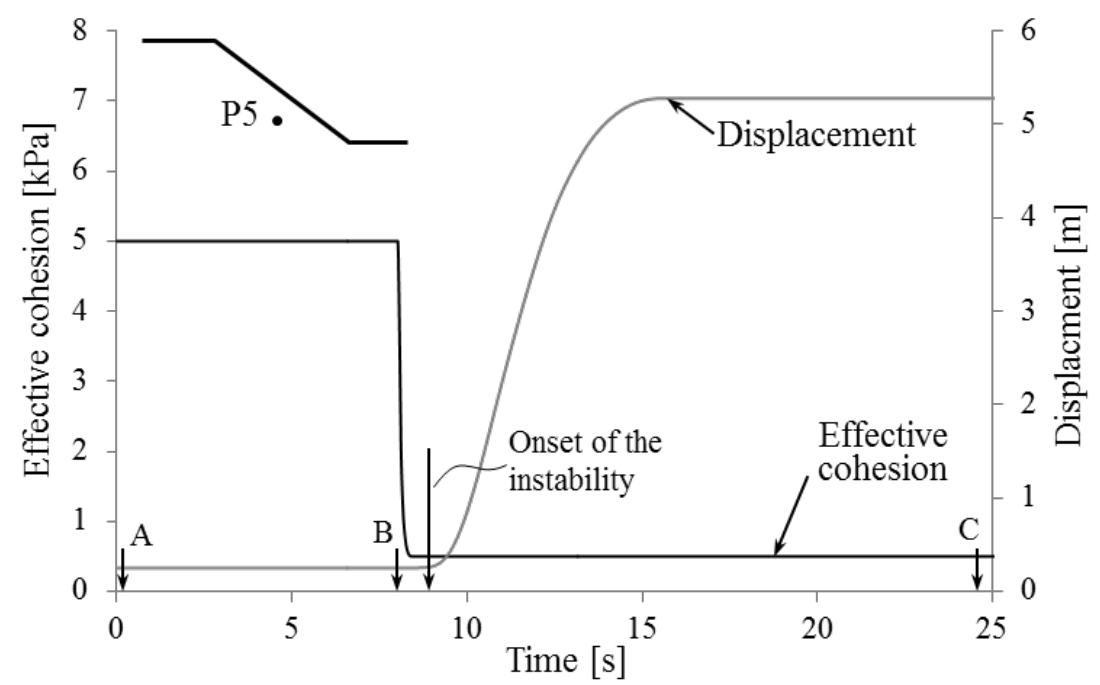

(a) 


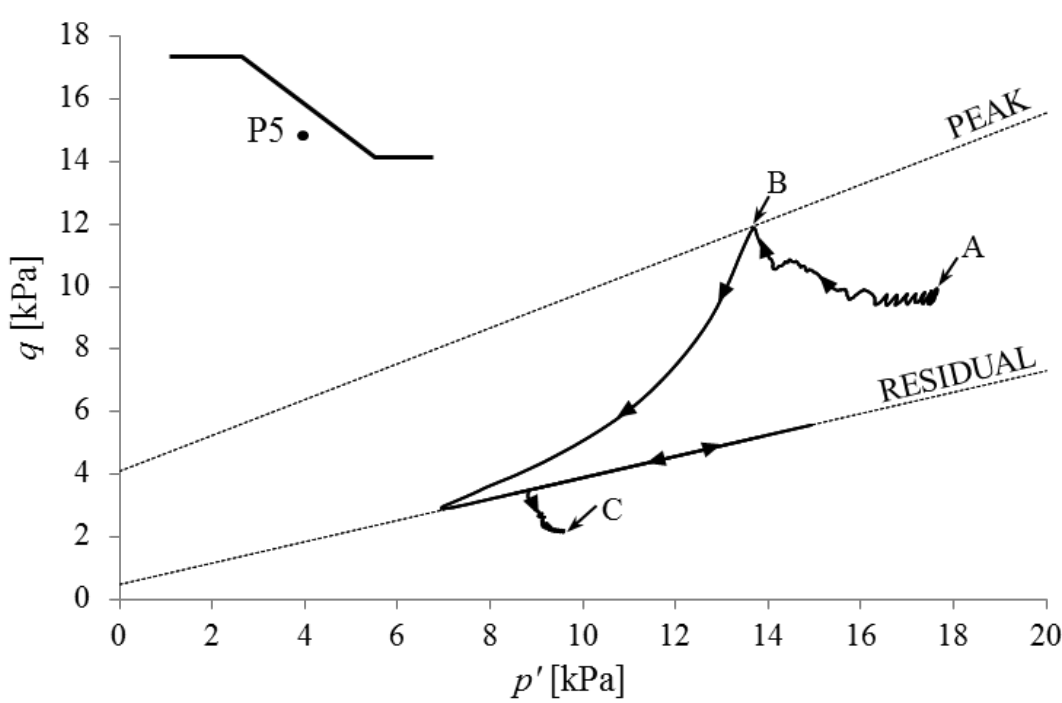

(b)

Fig. 7. Evolution of a material point located on the sliding surface. (a) Effective cohesion and calculated displacement; (b) Stress path in terms of deviatoric stress $q$ and mean effective stress $p$ '.

\section{PARAMETRIC STUDY AND RESULTS}

A parametric study was carried out with the aim of studying the slope stability and the postfailure behaviour as a function of the soil brittleness.

The brittleness of the soil is defined in terms of the brittleness index $\left(I_{B}\right)$ proposed by Bishop (1967). It is a measure of the decrease of the strength from a peak value $\left(\tau_{p}\right)$ to a residual one $\left(\tau_{r}\right)$ and it ranges from 0 to 1 .

$$
I_{B}=\frac{\tau_{p}-\tau_{r}}{\tau_{p}}
$$

where

$$
\tau_{p}=c_{p}^{\prime}+\bar{\sigma}_{n}^{\prime} \tan \phi_{p}^{\prime}
$$

$$
\tau_{r}=c_{r}^{\prime}+\bar{\sigma}_{n}^{\prime} \tan \phi_{r}^{\prime}
$$

Being $\bar{\sigma}_{n}^{\prime}$ the average of the normal stresses to the sliding surface distributed along the initial failure mechanism at the moment in which the global failure develops. This means that $I_{B}$ is not a local parameter but it is a global measure of the material brittleness, and therefore, a representative value of $I_{B}$ can be calculated for each simulation that becomes unstable. For stable slopes in which a sliding surface cannot be defined, it is not possible to determine $I_{B}$.

A total of 82 simulations have been calculated considering different values of peak and residual strengths. The initial geometry is the same for all of them and it is identical to the case described 
279 previously. Two different maximum excess pore pressures $(\Delta P)$ were introduced at the lower 280 boundary, 40 and $70 \mathrm{kPa}$, to examine the effect of the destabilizing action on the slide run-out 281 and velocity. Common material properties were given in Table 1. The strength parameters that 282 vary for each particular case are indicated in Tables 2 and 3. Note that the selection of the 283 strength values is not intended to strictly represent a certain type of soil but a strain softening material.

285 In order to evaluate the post-failure slope response, the run-out is an important parameter to 286 determine. Published data on run-out, based on simple approaches, consider a landslide 287 represented by the centre of mass of the total mobilised volume, hence the run-out calculated in 288 those cases is considered as the movement of such a point [51-53]. However, these models do 289 not consider the changes in geometry that may experience the moving mass during the 290 instability.

291 In this paper, run-out is defined as the distance between the toe of the initial slope and the toe of 292 the slope after failure once equilibrium has been re-established. This is a convenient parameter 293 to evaluate the extent of the slide and it is directly related with the associated risk. It is 294 important to highlight that this definition is not necessarily equivalent to the maximum 295 displacement achieved by any point of the slope.

\subsection{Common peak strength and varying residual friction}

297 Accepting a common peak envelope defined by $c_{p}{ }^{\prime}=5 \mathrm{kPa}$ and $\varphi_{p}{ }^{\prime}=35^{\circ}, 61$ simulations have 298 been carried out in order to study the effect of residual strength on the onset of instability and 299 post-failure behaviour. A list of these numerical simulations is presented in Table 2, in which 300 values of $I_{B}$ and run-out are also indicated.

301 A comparison between initial failure mechanisms obtained with MPM and with a Limit 302 Equilibrium Method LEM (Morgensten-Price) is shown in Fig. 8. The shape of the failure 303 surfaces is very similar to LEM prediction when considering peak strength values. However, the 304 depth of the failure surface slightly depends on the case simulated, ie.: the higher $c_{r}$ ', the deeper 305 the failure surface. More will be said below on the appropriate value of strength parameters to 306 be used in LEM in the case of brittle soils. 


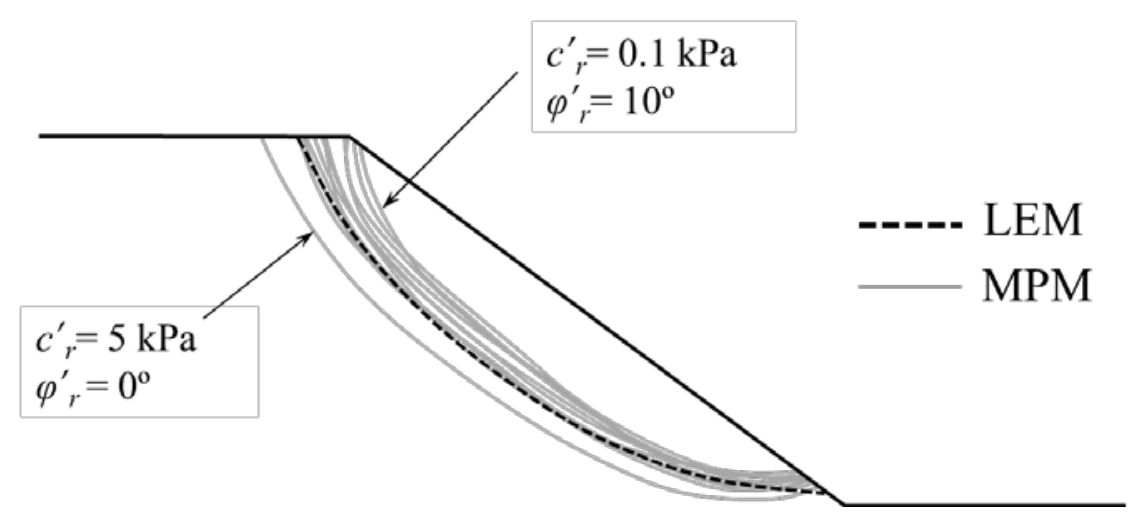

Fig. 8. Comparison between the initial failure mechanisms obtained using MPM and LEM analysis.

Fig. 9a shows the correlation between run-out and $I_{B}$. The results converge in a unique curve which indicates that run-out increases with $I_{B}$. Note that the maximum run-out observed in this parametric analysis is limited by the right boundary of the computational domain (Fig. 3). Therefore, the maximum run-out calculated is $26 \mathrm{~m}$. Moreover, when $I_{B}>0.75$, mobilised material points abandon the dense computational mesh and enter into a rougher mesh (Fig. 3). In these cases the integration becomes less accurate and results may be slightly less reliable.

If the maximum displacement achieved by a point of the slope is considered as a suitable indication of the slide displacement instead of the defined run-out, a similar trend of results is observed in Fig. 9b. However the dispersion is significantly higher in this case.

Note that different values of pore water pressure increase $(\Delta P)$ lead to the same $I_{B}$-run-out relationship (Fig. 9a). However, the minimum brittleness index required to induce instability ( $\left.\hat{I}_{B}\right)$ varies with $\Delta P$. If $\Delta P=40 \mathrm{kPa}, \hat{I}_{B}$ is around $0.5\left(\hat{I}_{B}^{40}\right)$, whereas for $\Delta P=70 \mathrm{kPa}$ it decreases to $0.22\left(\hat{I}_{B}^{70}\right)$. The higher the intensity of the triggering mechanism the lower the $I_{B}$ to induce instability.

Fig. 10 shows the final geometries of two simulations characterised by the same value of $I_{B}$. Despite having a similar value of the run-out $(14 \mathrm{~m})$, the maximum displacements are very different (9 and $13 \mathrm{~m}$ ) as well as the distribution of final displacements. Materials having a low residual cohesion $c_{r}$ ' lead to shallow failures (Fig. 10b), while higher residual cohesion results in a deeper failure and a rotational pattern (Fig. 10a).

Table 2. Run-out and $I_{B}$ for all simulations performed with a common peak strength envelope $\left(c_{p}{ }^{\prime}=5 \mathrm{kPa}\right.$ and $\left.\varphi_{p}{ }^{\prime}=35^{\circ}\right)$ for different residual strengths and two water pressure recharges $(\Delta P)$.

\begin{tabular}{|c|c||c|c|c|c|}
\multicolumn{1}{c||}{} & \multicolumn{4}{c|}{$c_{p}{ }^{\prime}=5 \mathrm{kPa} \varphi_{p}{ }^{\prime}=35^{\circ}$} \\
\cline { 3 - 6 } \multicolumn{2}{l||}{} & \multicolumn{2}{c|}{$\Delta P=40 \mathrm{kPa}$} & \multicolumn{2}{c|}{$\Delta P=70 \mathrm{kPa}$} \\
\hline$C_{r}{ }^{\prime}[\mathrm{kPa}]$ & $\varphi_{r}{ }^{\circ}\left[{ }^{\circ}\right]$ & $I_{B}$ & Run-out [m] & $I_{B}$ & Run-out [m] \\
\hline \hline 5 & 35 & stable & 0.0 & stable & 0.0 \\
5 & 25 & stable & 0.0 & stable & 0.0 \\
\hline
\end{tabular}




\begin{tabular}{|c|c|c|c|c|c|}
\hline 5 & 20 & & & 0.32 & 1.4 \\
\hline 5 & 15 & stable & 0.0 & 0.43 & 3.4 \\
\hline 5 & 10 & & & 0.54 & 6 \\
\hline 5 & 5 & stable & 0.0 & 0.63 & 11.6 \\
\hline 5 & 0 & 0.68 & 14.5 & & \\
\hline 4 & 30 & & & stable & 0.0 \\
\hline 4 & 25 & & & 0.28 & 1.45 \\
\hline 4 & 20 & & & 0.39 & 2.8 \\
\hline 4 & 15 & & & 0.48 & 5.2 \\
\hline 2.5 & 35 & stable & 0.0 & 0.22 & 0.7 \\
\hline 2.5 & 30 & & & 0.33 & 2.25 \\
\hline 2.5 & 25 & & & 0.41 & 3.35 \\
\hline 2.5 & 20 & stable & 0.0 & 0.49 & 5.26 \\
\hline 2.5 & 15 & 0.57 & 6.9 & 0.57 & 8.25 \\
\hline 2.5 & 10 & 0.66 & 12.1 & 0.67 & 12.7 \\
\hline 2.5 & 5 & 0.74 & 14.9 & 0.75 & 17 \\
\hline 2.5 & 0 & 0.83 & 25 & 0.87 & 21.1 \\
\hline 1.5 & 30 & & & 0.37 & 2.92 \\
\hline 1.5 & 25 & & & 0.46 & 4.86 \\
\hline 1.5 & 20 & & & 0.56 & 6.45 \\
\hline 1.5 & 15 & & & 0.64 & 10 \\
\hline 1.5 & 10 & & & 0.73 & 14.6 \\
\hline 1.2 & 25 & stable & 0.0 & 0.5 & 5.7 \\
\hline 1.2 & 20 & 0.58 & 7 & 0.6 & 7.5 \\
\hline 1.2 & 15 & 0.67 & 11.2 & 0.67 & 11.7 \\
\hline 1.2 & 10 & 0.75 & 14.8 & 0.75 & 15.6 \\
\hline 0.5 & 35 & stable & 0.0 & 0.39 & 3.5 \\
\hline 0.5 & 30 & stable & 0.0 & 0.45 & 5.4 \\
\hline 0.5 & 25 & 0.58 & 7 & 0.55 & 6.5 \\
\hline 0.5 & 20 & 0.65 & 9.5 & 0.63 & 8.9 \\
\hline 0.5 & 15 & 0.72 & 14 & 0.7 & 13.01 \\
\hline 0.5 & 10 & 0.8 & 20 & 0.79 & 17.5 \\
\hline 0.1 & 35 & stable & 0.0 & & \\
\hline 0.1 & 30 & 0.52 & 6 & & \\
\hline 0.1 & 25 & 0.62 & 8.8 & & \\
\hline 0.1 & 20 & 0.68 & 12.6 & & \\
\hline 0.1 & 15 & 0.76 & 17.4 & & \\
\hline 0.1 & 10 & 0.83 & 26 & & \\
\hline 0.1 & 5 & 0.91 & 26 & & \\
\hline
\end{tabular}

330 Fig. 11 illustrates the final geometries after failure for 5 simulations with the same $c_{r}{ }^{\prime}=0.5 \mathrm{kPa}$.

331 The same pattern of displacements is observed in all cases. However, the run-out increases and

332 the slope becomes flatter with increasing values of brittleness.

333 In order to highlight the dynamics of the failure, Fig. 12 shows the evolution of the 334 displacement (Fig. 12a) and the velocity (Fig. 12b) of a material point initially located just 335 above the initial shear band. These results correspond to the unstable simulations presented 336 previously in Fig. 11. These plots illustrate different phases of an instability process. 
337 The patterns of displacements, after a sliding mechanism was fully developed, follow the 338 description given when interpreting Figures 6 and 7a. Figure 12a shows the effect of $I_{B}$ on 339 displacements of point $\mathrm{P}$, located at the lower part of the slope. Velocities are also given in 340 Figure 12b. The slide accelerates, reaches a maximum velocity and moves forward towards a 341 new stable profile.

342 Additionally it can be observed that in slopes exhibiting larger values of $I_{B}$, for the same peak 343 strength: (1) the instability occurs earlier; (2) the velocity increases more suddenly; (3) the peak 344 velocities reach higher values; (4) more time is required to reach the final position at rest; and 345 (5) the run-out is longer.

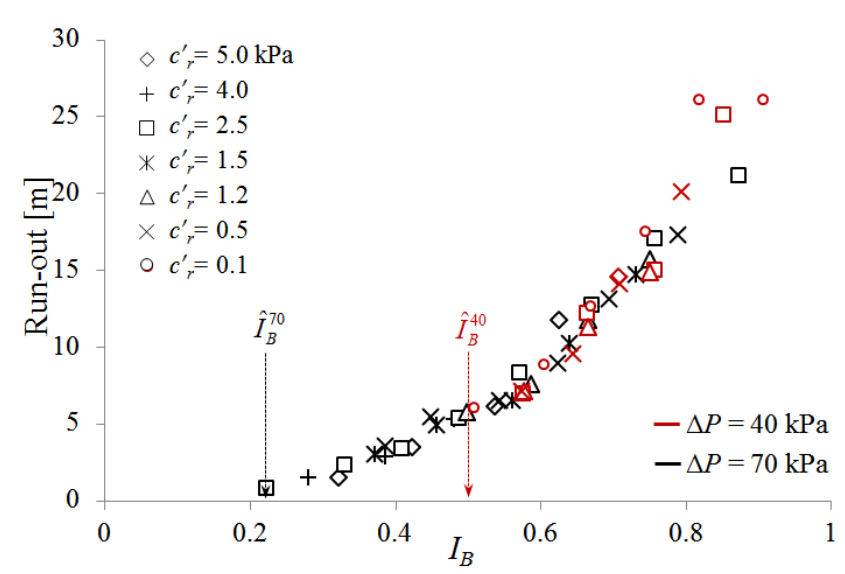

(a)

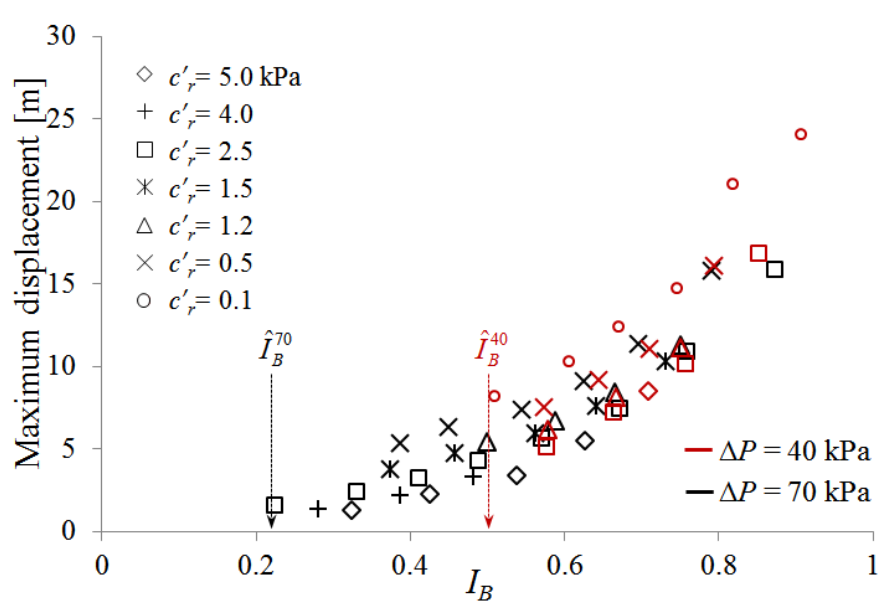

(b)

Fig. 9. (a) Relationship between run-out and $I_{B}$. (b) Relationship between maximum displacement indicates the imposed pore water pressure which induced the failure. 


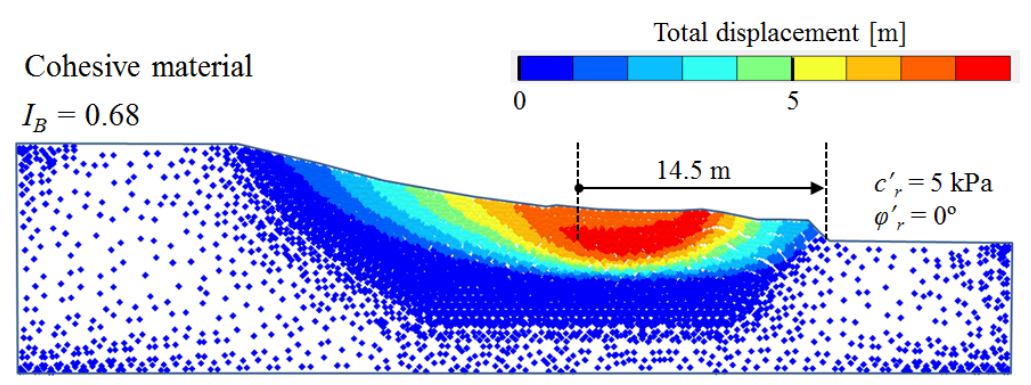

(a)

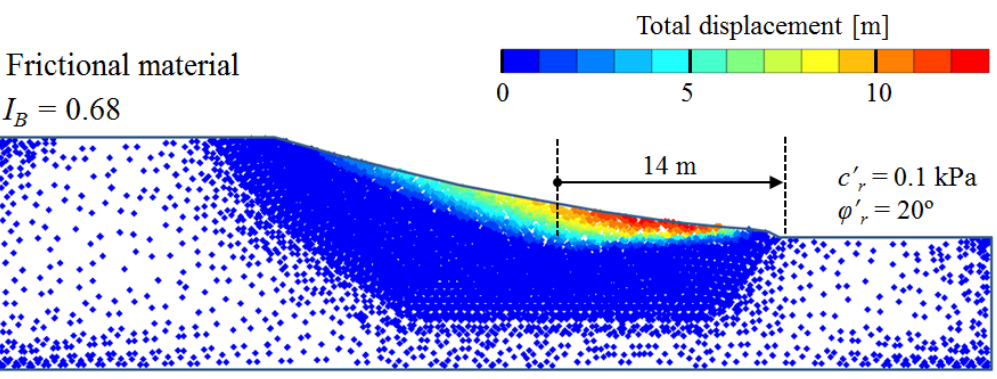

(b)

Fig. 10. Final geometry for two simulations with same $I_{B}$. The displacements of the material points are indicated in the colour scales. Also indicated is the run-out.

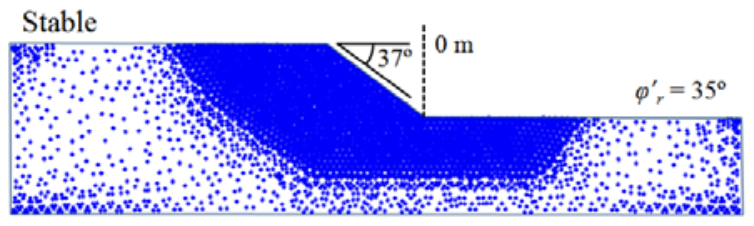

(a)

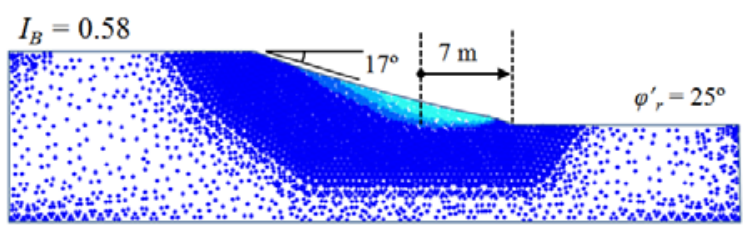

(b)

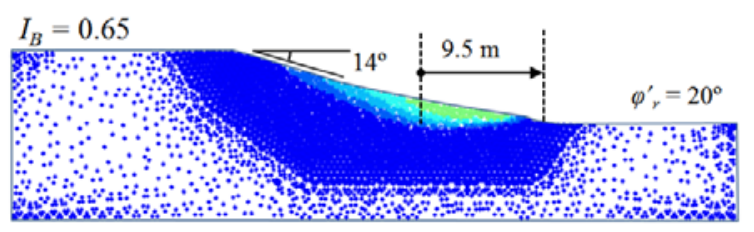

(c)
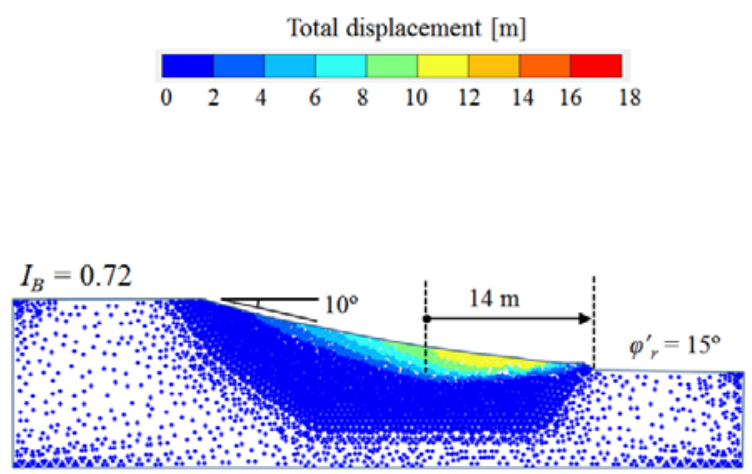

(d)

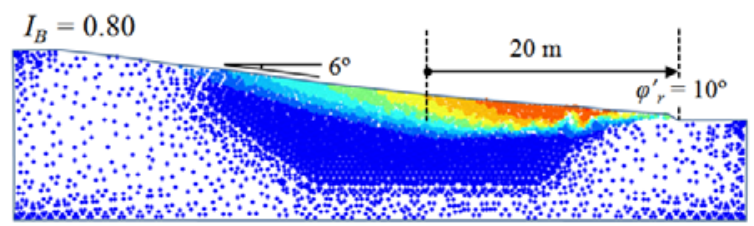

(e)

Fig. 11. Final geometries of simulations with $C_{r}{ }^{\prime}=0.5 \mathrm{kPa}$. The displacements of the material points are indicated in the indicated colour scale. Also indicated is the run-out. 


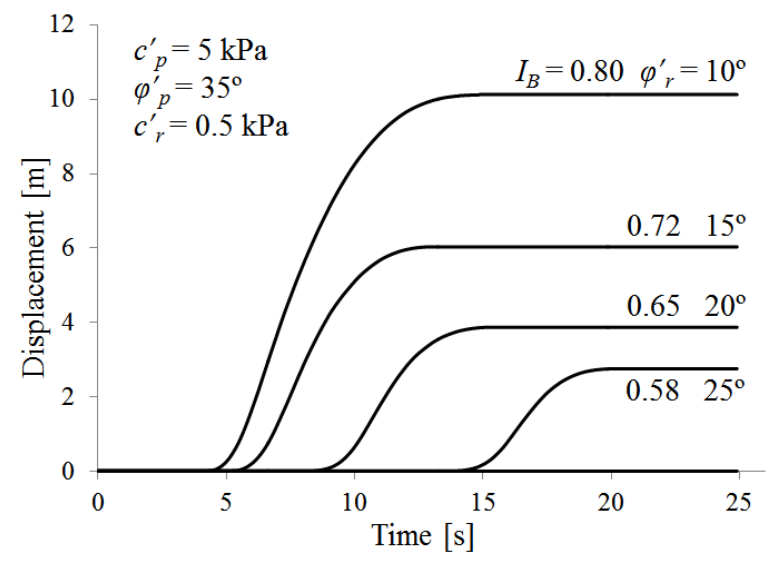

(a)

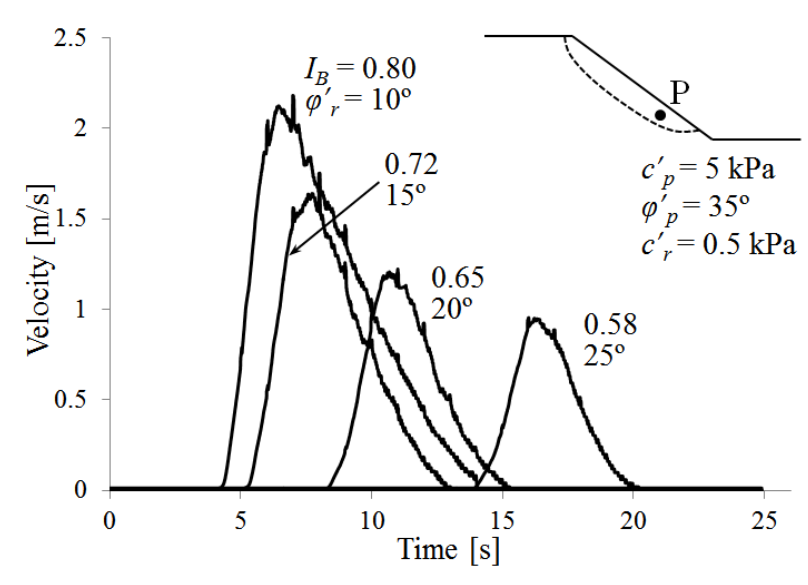

(b)

Fig. 12. (a) Displacement and (b) velocity of the material point $\mathrm{P}$ for simulations characterized by $c_{r}{ }^{\prime}=0.5$ $\mathrm{kPa}$.

\subsection{Change in peak strength and varying residual friction}

364

365

366

367

368

369

370

371

372

373

In the previous Section it was found that a unique relationship developed between run-out and $I_{B}$ when the peak friction strength envelope was constant (and the residual strength varied in a wide range). The next step was to check if such uniqueness would also hold if peak strength parameters change. In order to explore this scenario three different peak strength parameters were selected, rather arbitrarily, but always ensuring that the slope would fail under the imposed water pressure increase at the lower boundary ( $\triangle P=70 \mathrm{kPa}$,):

- $\quad c_{p}{ }^{\prime}=5 \mathrm{kPa}, \varphi_{p}{ }^{\prime}=35^{\circ}$ (already analysed in the previous section)

- $\quad c_{p}{ }^{\prime}=5 \mathrm{kPa}, \varphi_{p}{ }^{\prime}=45^{\circ}$

- $\quad c_{p}{ }^{\prime}=9 \mathrm{kPa}, \varphi_{p}{ }^{\prime}=20^{\circ}$

For each case, several simulations have been carried out varying the residual strength parameters according to Table 3.

Following the procedure described previously, the brittleness index $I_{B}$ has been calculated for each unstable simulation. The effect of $I_{B}$ on run-out is presented in Fig. 13a. Although it is clear that the run-out increases for increasing $I_{B}$, two different relationships can be distinguished. Whereas the combination of $c_{p}{ }^{\prime}=5 \mathrm{kPa}$ and $\varphi_{p}{ }^{\prime}=45^{\circ}$ matches with the correlation defined in Fig. 9a, those simulations with $c_{p}{ }^{\prime}=9 \mathrm{kPa}$ and $\varphi_{p}{ }^{\prime}=20^{\circ}$ define higher run-outs. Fig. 13b shows the variation of the maximum displacement achieved by a point depending on $I_{B}$, and, as shown in Fig. 9b, the scatter increases especially for higher values of $I_{B \text {. }}$

Since the obtained $I_{B}$-run-out relationship (Fig. 13) is not unique, three simulations with different peak strengths and the same $I_{B}$ are analysed in detail (Figs. 14 and 15). The evolution of strain contours (Fig. 14) indicates that the shear strains localise along a single band in the first two simulations (Figs. 14a and 14b). By contrast, a deeper mechanism is developed in the 
third simulation (Fig. 14c) which is characterized by a higher cohesion and a lower friction

387 angle with respect to the other two cases. A deeper seated failure involves a larger volume of the 388 mobilized mass and also a longer length of the sliding surface. It seems that the $I_{B}$-run-out 389 relationship is also dependent on the failure mechanism. Final displacement fields are given in 390 Fig. 15. Note that values of run-out and maximum displacements are different.

391 Table 3. Run-out and $I_{B}$ for all simulations performed with three peak yield surface envelopes.

\begin{tabular}{|c|c|c|c|c|c|c|c|}
\hline \multirow[b]{3}{*}{$c_{r}^{\prime}[\mathrm{kPa}]$} & \multirow[b]{3}{*}{$\varphi_{r}{ }^{\prime}\left[{ }^{\circ}\right]$} & \multicolumn{6}{|c|}{$\Delta P=70 \mathrm{kPa}$} \\
\hline & & \multicolumn{2}{|c|}{$c_{p}{ }^{\prime}=5 \mathrm{kPa} \varphi_{p}{ }^{\prime}=35^{\circ}$} & \multicolumn{2}{|c|}{$c_{p}^{\prime}=5 \mathrm{kPa} \varphi_{p}^{\prime}=45^{\circ}$} & \multicolumn{2}{|c|}{$c_{p}{ }^{\prime}=9 \mathrm{kPa} \varphi_{p}{ }^{\prime}=20^{\circ}$} \\
\hline & & $I_{B}$ & Run-out [m] & $I_{B}$ & Run-out [m] & $I_{B}$ & Run-out [m] \\
\hline 6 & 20 & & & & & stable & 0.0 \\
\hline 6 & 15 & & & & & 0.3 & 1.45 \\
\hline 6 & 10 & & & & & 0.42 & 4.8 \\
\hline 6 & 5 & & & & & 0.56 & 13.41 \\
\hline 5 & 35 & stable & 0.0 & & & & \\
\hline 5 & 25 & stable & 0.0 & & & & \\
\hline 5 & 20 & 0.32 & 1.4 & & & 0.25 & 1.3 \\
\hline 5 & 15 & 0.43 & 3.4 & & & 0.36 & 3 \\
\hline 5 & 10 & 0.54 & 6 & & & 0.48 & 8.7 \\
\hline 5 & 5 & 0.63 & 11.6 & & & 0.63 & 15 \\
\hline 5 & 0 & & & & & & \\
\hline 4 & 30 & stable & 0.0 & & & & \\
\hline 4 & 25 & 0.28 & 1.45 & & & & \\
\hline 4 & 20 & 0.39 & 2.8 & & & & \\
\hline 4 & 15 & 0.48 & 5.2 & & & & \\
\hline 2.5 & 35 & 0.22 & 0.7 & & & & \\
\hline 2.5 & 30 & 0.33 & 2.25 & & & & \\
\hline 2.5 & 25 & 0.41 & 3.35 & & & & \\
\hline 2.5 & 20 & 0.49 & 5.26 & & & 0.38 & 5.37 \\
\hline 2.5 & 15 & 0.57 & 8.25 & & & 0.5 & 9 \\
\hline 2.5 & 10 & 0.67 & 12.7 & & & 0.63 & 13.9 \\
\hline 2.5 & 5 & 0.75 & 17 & & & & \\
\hline 2.5 & 0 & 0.87 & 21.1 & & & & \\
\hline 1.5 & 30 & 0.37 & 2.92 & & & & \\
\hline 1.5 & 25 & 0.46 & 4.86 & & & & \\
\hline 1.5 & 20 & 0.56 & 6.45 & 0.65 & 9.3 & 0.46 & 8 \\
\hline 1.5 & 15 & 0.64 & 10 & & & 0.57 & 12.55 \\
\hline 1.5 & 10 & 0.73 & 14.6 & & & 0.68 & 17.02 \\
\hline 1.2 & 25 & 0.5 & 5.7 & & & & \\
\hline 1.2 & 20 & 0.6 & 7.5 & & & & \\
\hline 1.2 & 15 & 0.67 & 11.7 & & & & \\
\hline 1.2 & 10 & 0.75 & 15.6 & & & & \\
\hline 0.5 & 35 & 0.39 & 3.5 & & & & \\
\hline 0.5 & 30 & 0.45 & 5.4 & & & & \\
\hline 0.5 & 25 & 0.55 & 6.5 & 0.65 & 10 & & \\
\hline 0.5 & 20 & 0.63 & 8.9 & 0.7 & 13.1 & 0.52 & 12.7 \\
\hline 0.5 & 15 & 0.7 & 13.01 & 0.77 & 15.4 & 0.61 & 15.07 \\
\hline 0.5 & 10 & 0.79 & 17.5 & 0.84 & 19.5 & & \\
\hline
\end{tabular}


393

394

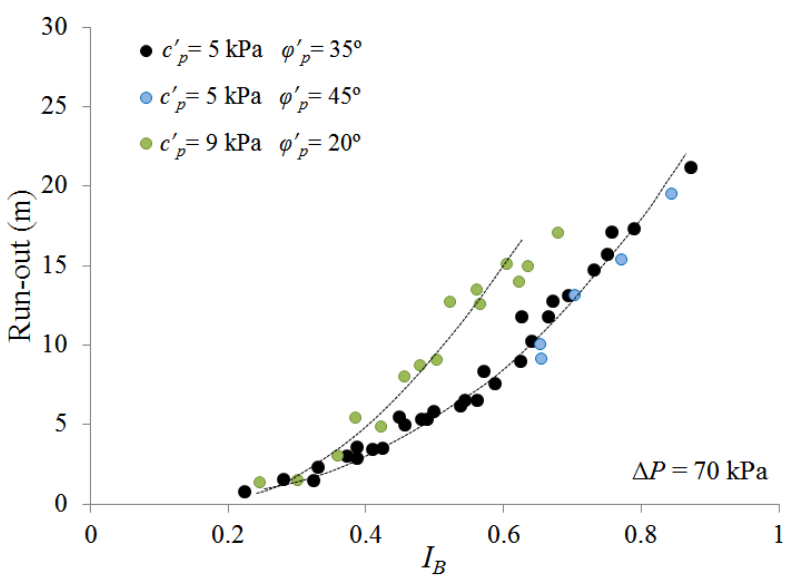

(a)

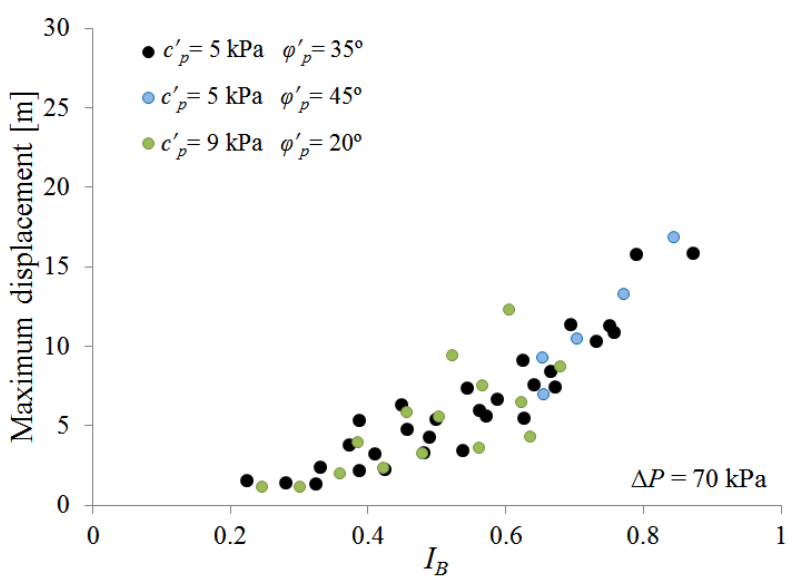

(b)

Fig. 13. Relationships between $I_{B}$ and (a) run-out and (b) maximum displacement achieved by a point.
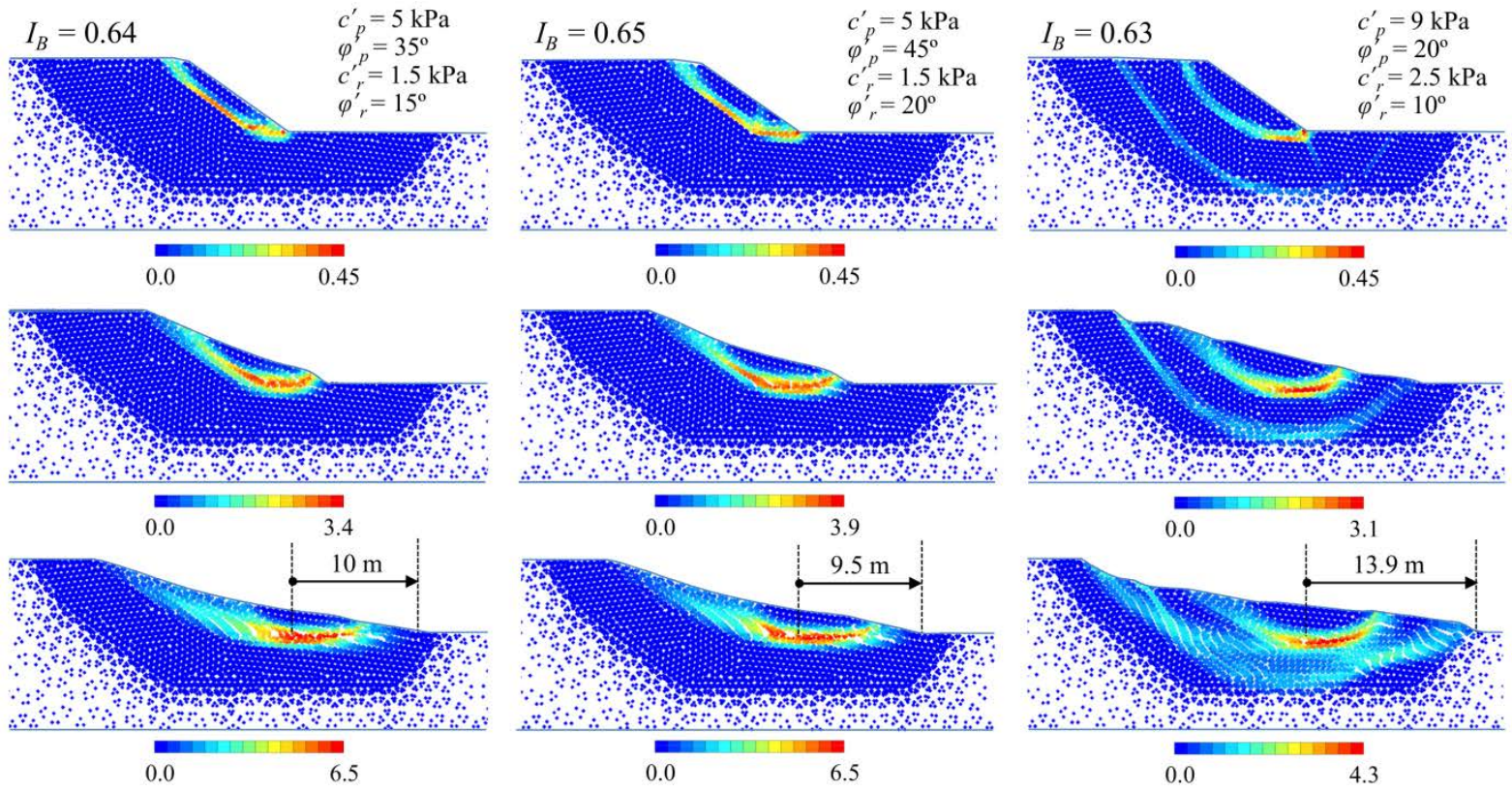

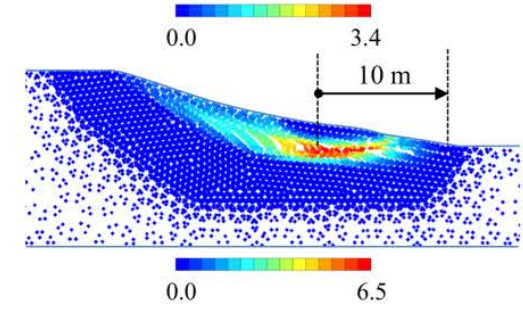

(a)

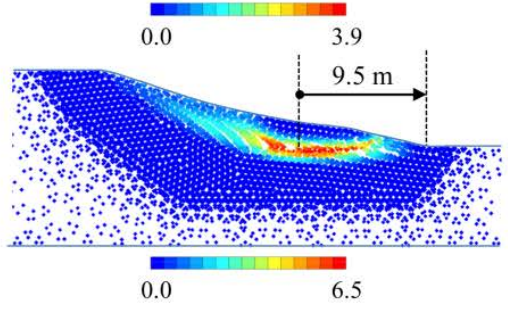

(b)

(c)

Fig. 14. Distribution of the shear strain at three different times (the initiation of failure mechanism, an intermediate time, and final geometry) for three simulations with similar $I_{B}$ but different peak strength envelopes.(a) $c_{p}{ }^{\prime}=5 \mathrm{kPa}, \varphi_{p}{ }^{\prime}=35^{\circ}$; (b) $c_{p}{ }^{\prime}=5 \mathrm{kPa} ; \varphi_{p}{ }^{\prime}=45^{\circ}$; (c) $c_{p}{ }^{\prime}=9 \mathrm{kPa}, \varphi_{p}{ }^{\prime}=20^{\circ}$.

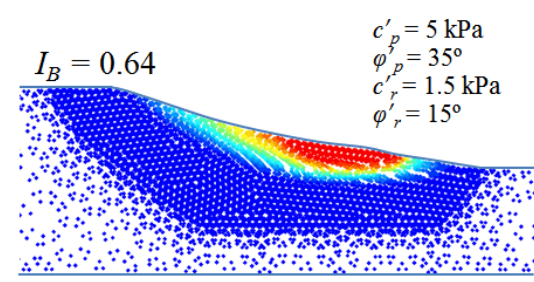

(a)

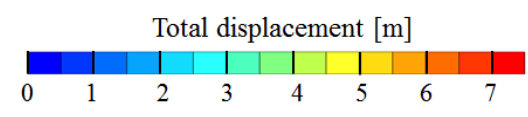

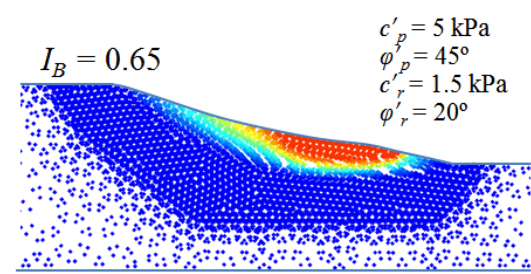

(b)

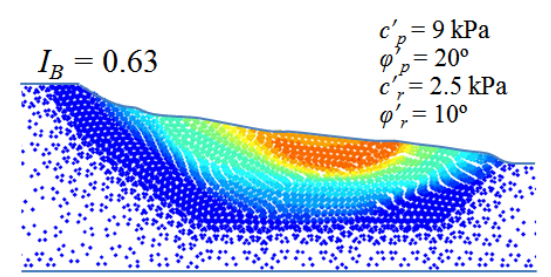

(c) 

strengths. (a) $c_{p}{ }^{\prime}=5 \mathrm{kPa}, \varphi_{p}{ }^{\prime}=35^{\circ}$; (b) $c_{p}{ }^{\prime}=5 \mathrm{kPa}, \varphi_{p}{ }^{\prime}=45^{\circ}$; (c) $c_{p}{ }^{\prime}=9 \mathrm{kPa}, \varphi_{p}{ }^{\prime}=20^{\circ}$.

406

407

408

409

410

411

412

413

414

415

416

417

418

419

420

421

422

423

\subsection{Effect of cohesion and friction angle decrease in the onset of failure}

The onset of failure is analysed depending on the cohesion and friction decrease (Eqs. (10) and (11) respectively) and on the external triggering action (pore water pressure increase in the lower boundary $\Delta P$ ). Consider the following "brittleness" ratios for effective cohesion and friction:

$$
d c^{\prime}=\left(c_{p}^{\prime}-c_{r}^{\prime}\right) / c_{p}^{\prime}
$$

$$
d \varphi^{\prime}=\left(\tan \varphi_{p}^{\prime}-\tan \varphi_{r}^{\prime}\right) / \tan \varphi_{p}^{\prime}
$$

Zero values of these indices corresponds to a ductile behaviour whereas a unit value represents a highly brittle response.

All the combinations of $d c^{\prime}$ and $d \varphi^{\prime}$ shown in Table 2 for $\Delta P=40 \mathrm{kPa}$ and $\Delta P=70 \mathrm{kPa}$ are shown in Fig. 16. It is clear that the lower the increments of water pressure, the higher is the required strength reduction to make the slope unstable. For instance, in the case of $\Delta P=40 \mathrm{kPa}$, in order to reach failure, the soil should exhibit a full brittleness in one of the strength parameters and a full ductility in the other, or the combination given by the threshold straight line separating failure from stability.

These results suggest that both cohesion and friction angle play a similar role in determining a threshold that define whether the slope will become unstable, or on the contrary, will remain stable.

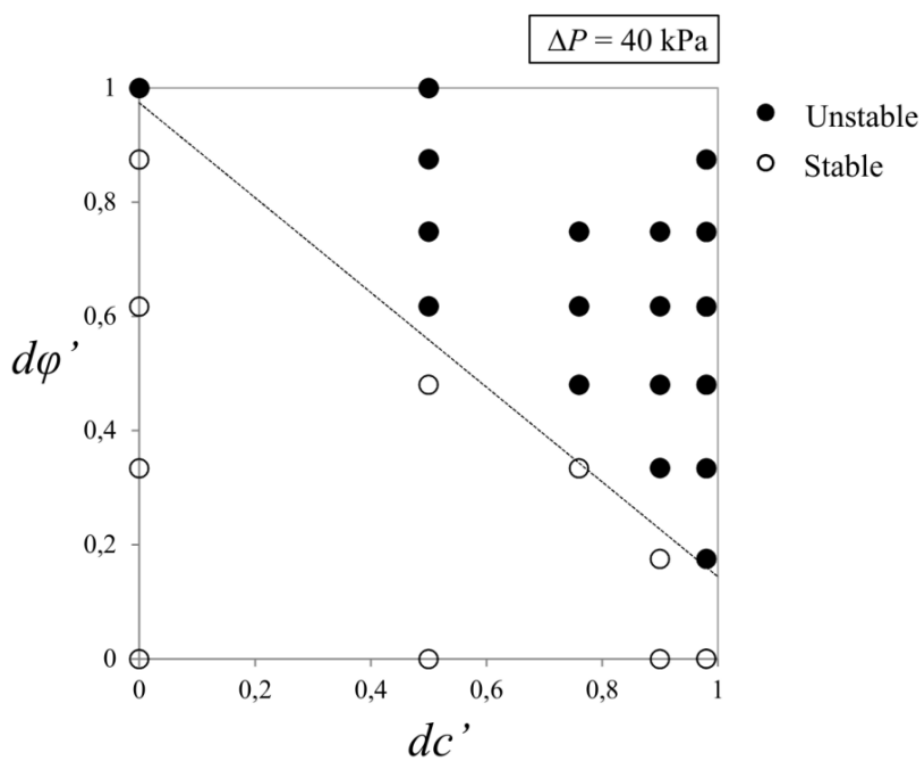




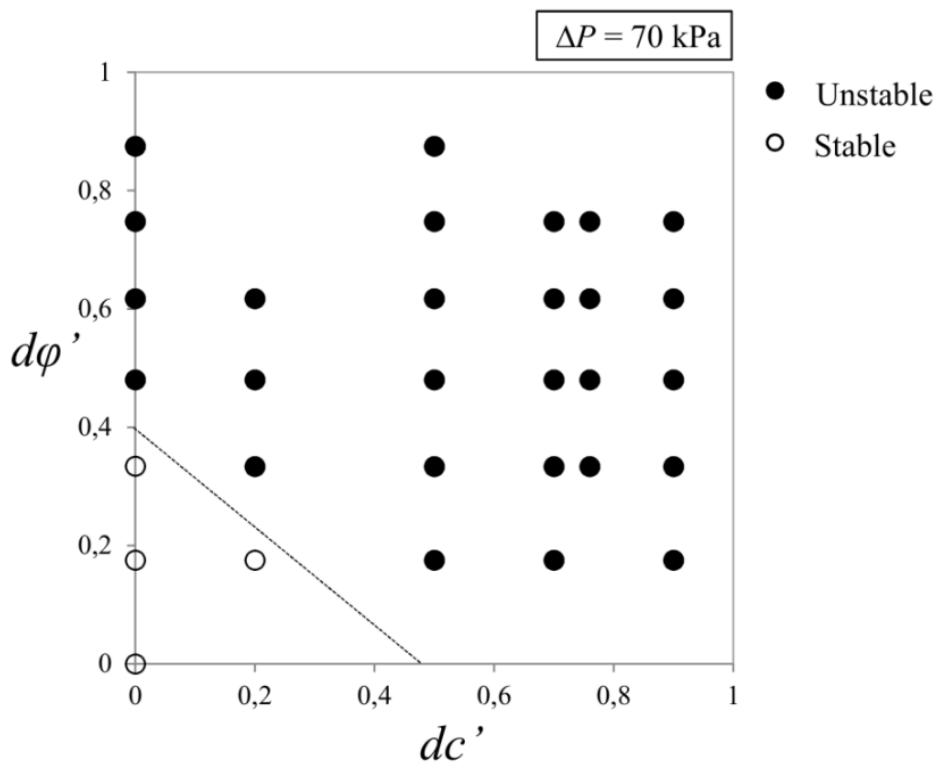

(b)

Fig. 16. Stability of the slope depending on the combination of cohesion drop $\left(d c^{\prime}\right)$ and friction angle decrease ( $\left.d \varphi^{\prime}\right)$. The increase of pore pressure at at the lower boundary is (a) $\Delta P=40 \mathrm{kPa}$ and (b) $\Delta P=70$ $\mathrm{kPa}$. The same peak strength is maintained in all these simulations $\left(c_{p}{ }^{\prime}=5 \mathrm{kPa}\right.$ and $\left.\varphi_{p}{ }^{\prime}=35^{\circ}\right)$.

\subsection{Effect of peak and residual strength in run-out}

In previous sections, the $I_{B}$-run-out relationship is analysed but the relevance of peak and residual strength is not discussed. This is because $I_{B}$ combines both effects in a single parameter.

The influence of peak and residual strengths on the value of run-out is shown in Fig. 17. It is clear that simulations having the same residual strength have quite similar values of run-out even if different peak yield surface envelopes define the material (Fig. 17).

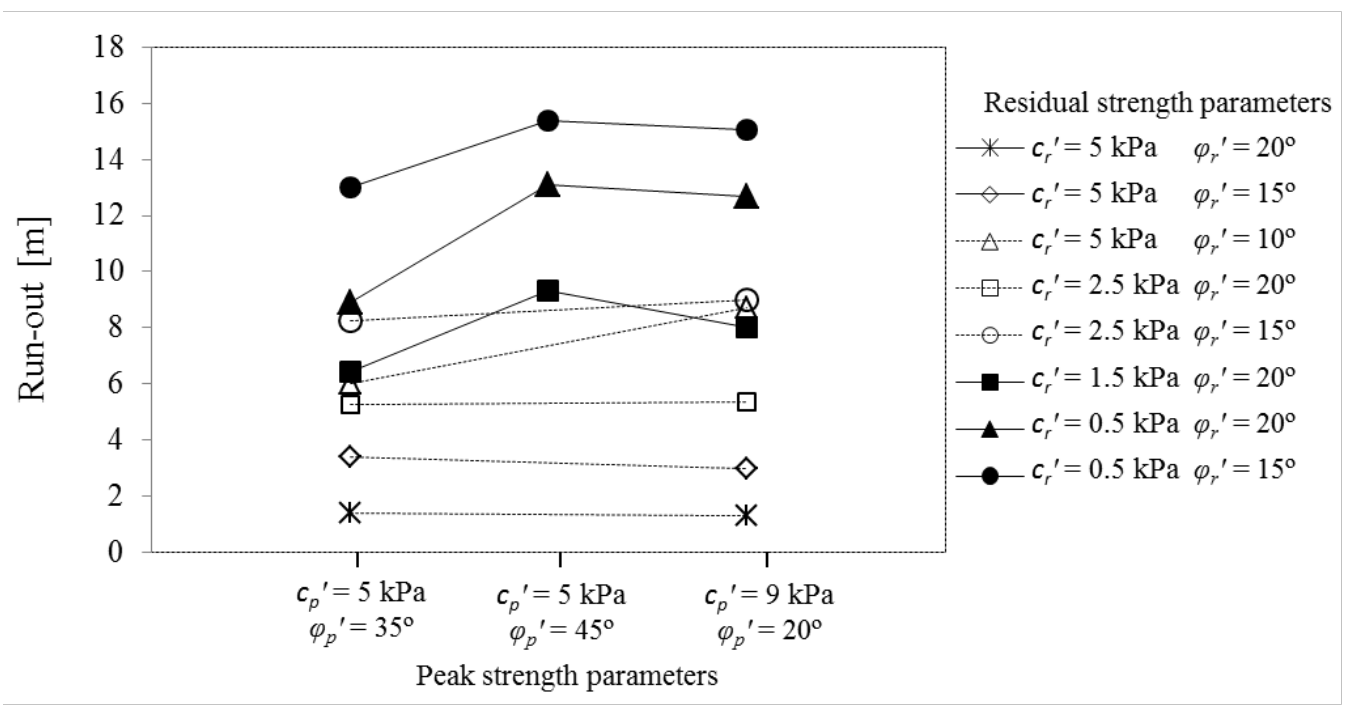

Fig. 17. Influence of residual strength on run-out for three different peak Mohr-Coulomb envelopes. 


\subsection{Run-out vs maximum displacement}

441 It has been shown that run-out, defined as the distance between the toe of the initial slope and

442 the toe once equilibrium has been re-established after the instability, is not equivalent to the 443 maximum displacement achieved by any point of the slope (see Figs. 9 and 13). While a clear 444 relationship cannot be obtained between $I_{B}$ and maximum displacement, $I_{B}$ and run-out correlate 445 well.

446 The difference between run-out and maximum displacement is evident especially when the 447 failure mechanism is deep and the landslide is essentially a rotational movement (Fig. 10a). The 448 deeper the failure surface (cohesive component of strength dominates) the larger the ratio 449 between run-out and maximum point displacements. However, both lengths are similar when 450 the initial failure is shallow (Fig. 10b).

\subsection{Effect of peak and residual strength in the whole instability process}

Here the role played by peak and residual strengths in the stability of the slope, in the slip surface geometry and in the post-failure response is discussed.

According to the results presented in Fig. 6, it is clear that the peak envelope controls the initiation of the progressive failure because it determines when the first point reaches the maximum strength. However, the redistribution of stresses due to the strain softening of the material and the propagation of the progressive failure is a complex process governed by both peak and residual states. Note that the mean mobilised strength in the slope (Fig. 6b) remains always below the peak value.

In agreement with this, it has been observed that the geometry of the failure mechanism is definitely influenced by both peak and residual strengths (Figs. 8 and 14) but peak strength has a stronger effect. Especially the peak cohesion highly influences the depth of the mechanism.

463 Finally, the run-out is essentially influenced by the residual state (Fig. 17). It makes sense because when the post-failure stage initiates the soil in the shear band has experienced enough plastic shear strain to be totally softened. This behaviour is also shown in Fig. 6b.

\subsection{Residual cohesion in brittle soils}

467 In brittle soils, peak friction angles may take values ranging from $5^{\circ}$ to $45^{\circ}$ depending on the 468 type of soil. The variability of peak cohesion can be also very large (from $0 \mathrm{kPa}$ to more than, 
say, $200 \mathrm{kPa}$ in very stiff clays). However, residual effective cohesion is very low or nonexistent.

471 The selection of peak and strength values presented in the parametric analysis (Section 5)

472 represents a large variability of strain softening materials, and some of them include unlikely 473 values for the residual cohesion (up to $6 \mathrm{kPa}$ ).

474 In order to analyse if this restriction have some effect on the results, an additional figure is 475 included here (Fig. 18) in which only those simulations from Table 3 having a small $c_{r}{ }^{\prime}\left(c_{r}{ }^{\prime} \leq 1.5\right.$ $476 \mathrm{kPa}$ ) are presented. The number of cases in the simulations performed decrease substantially but the relationships between $I_{B}$ and run-out and maximum displacement look essentially the same as those obtained when interpreting the complete set of simulations (Fig. 13).

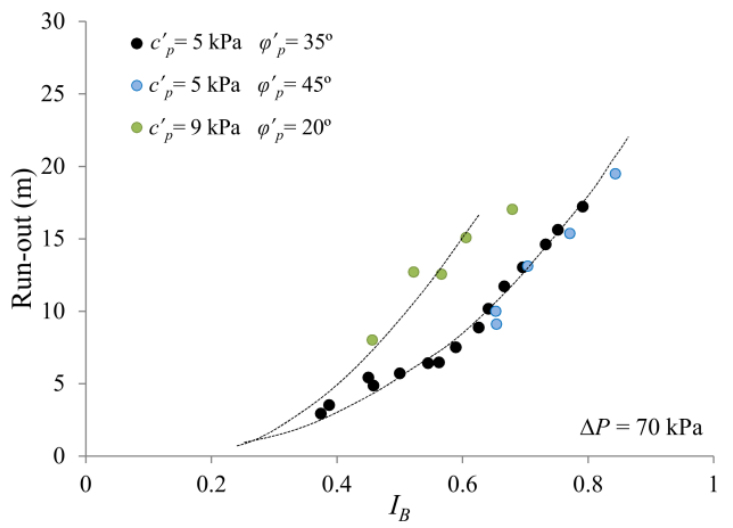

(a)

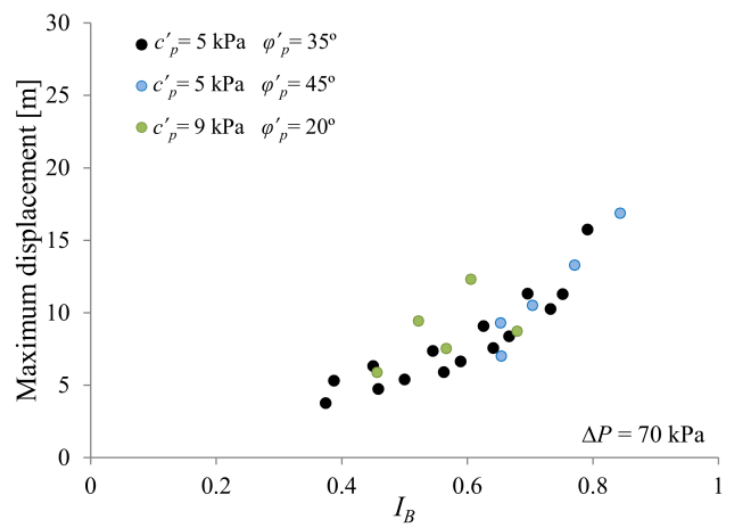

(b)

Fig. 18. Relationships between $I_{B}$ and (a) run-out and (b) maximum displacement achieved by a point. Cases with $c_{r}{ }^{\prime} \leq 1.5 \mathrm{kPa}$.

\section{CONCLUSIONS}

The stability and post-failure behaviour of a saturated slope have been analysed by means the MPM which has been proved that it is capable to simulate both the initiation of failure, which involves small strains, and the post-failure stage, generally characterised by large displacements. A homogeneous slope with a regular geometry has been analysed. The slope failure is triggered by increasing the water pressure on the lower boundary of the domain.

The slope material has been defined by a strain-softening elastoplastic constitutive law that allows the simulation of the strength decrease (from a peak to a residual value). The progressive failure mechanism, typically observed in brittle materials, is reproduced and analysed. Both, peak and residual values of the strength control the slope failure which progresses from the toe to the crest of the slope. On the contrary, the post-failure behaviour is mainly controlled by the 
residual strength and it has an important effect on the run-out. The results show that the geometry of the failure surface determines the final displacement field.

The effect of the material brittleness, defined in terms of brittleness index $I_{B}$ (proposed by Bishop [12]), on the post-failure behaviour has been identified by means of a parametric analysis combining peak and residual values of cohesion and friction angle. Both run-out and the maximum displacements have been represented in terms of the brittleness index. Run-out was defined here as the distance between the toe of the initial slope and the toe of the slope after failure once equilibrium has been re-established. It was found that run-out increases with $I_{B}$ and both correlate well when a common peak strength envelope is adopted. On the contrary, a clear relationship has not been obtained between $I_{B}$ and maximum displacement.

The onset of failure also depends on the magnitude of the triggering mechanism. The higher the intensity of the triggering mechanism, the lower $I_{B}$ is sufficient to induce instability. This fact allows defining a brittleness threshold $\hat{I}_{B}^{\Delta P}$ which determines the minimum brittleness required to induce instability for a certain excess pore pressure. However, the magnitude of the applied excess pressure $(\Delta P)$ does not change the general observations discussed above.

\section{ACKNOWLEGDMENTS}

The software used in this work is a version of the MPM code developed by the MPM Research Community formed by 6 partners: Deltares (The Netherlands), Universitat Politècnica de Catalunya (Spain), University of Cambridge (UK), Technische Universität Hamburg-Harburg (Germany), Università degli Studi di Padova (Italy), and Delft University of Technology (The Netherlands).

\section{REFERENCES}

[1] Fell R, Hungr O, Leroueil S, Riemer W. Keynote lecture - Geotechnical engineering of the stability of natural slopes, and cuts and fills in soil. ISRM Int. Symp., Melbourne, Australia: International Society for Rock Mechanics; 2000.

[2] Pinyol N, Alonso E, Corominas J, Moya J. Canelles landslide: modelling rapid drawdown and fast potential sliding. Landslides 2012;9:33-51.

[3] Alonso E, Gens A. The landslide of Cortes de Pallas, Spain. Géotechnique 1993;43:50721.

[4] Ganerød G, Grøneng G, Rønning J, Dalsegg E, Elvebakk H, Tønnesen J, et al. Geological model of the Åknes rockslide, western Norway. Eng Geol 2008;102:1-18.

[5] Qi S, Yan F, Wang S, Xu R. Characteristics, mechanism and development tendency of deformation of Maoping landslide after commission of Geheyan reservoir on the Qingjiang River, Hubei Province, China. Eng Geol 2006;86:37-51.

[6] Alcantara-Ayala I, Dominguez-Morales L. The San Juan de Grijalva catastrophic 
landslide, Chiapas, Mexico: lessons learnt. In: Casagli N, Fanti R, Tofani V, editors. Web Proc. First World Landslide Forum. Int. Consort. Landslides. United Nations Int. Strateg. Disaster Reductions, Tokyo, Japan: 2008, p. 96-9.

Wang F, Zhang Y, Huo A, Matsumoto T, Huang B. The July 14, 2003 Qianjiangping landslide, Three Gorges Reservoir, China. Landslides 2004;1:157-62.

[10] Skempton AW. Fourth Rankine Lecture: Long-term stability of clay slopes. Géotechnique 1964;14:77-102.

[11] Bjerrum L. Progressive failure in slopes in overconsolidated plastic clays and clay shales. J Soil Mech Found Div 1967;93:3-49.

[12] Bishop AW. Progressive failure-with special reference to the mechanism causing it. Proc. Geotech. Conf., vol. 2, Oslo: 1967, p. 142-50.

[13] Palmer C, Rice JR. The growth of slip surfaces in the progressive failure of overconsolidated clay. Proc R Soc A 1973;332:527-48.

[14] Stark TD, Eid HT. Slope stability analyses in stiff fissured clays. J Geotech Geoenv Engng 1994;123:335-43.

[15] Puzrin AM, Germanovich LN. The growth of shear bands in the catastrophic failure of soils. Proc R Soc A Math Phys Eng Sci 2005;461:1199-228. doi:10.1098/rspa.2004.1378.

[16] Yamaguchi H, Kimura T, Fuji-I N. On the influence of pregressive failures on the bearing capacity of shallow foundations in dense sand. Soils Found 1976;16:11-22.

[17] Potts DM, Dounias GT, R. VP. Finite element analysis of progressive failure of Carsington embankment. Géotechnique 1990;40:79-101.

[18] Potts D, Kovacevic N, Vaughan P. Delayed collapse of cut slopes in stiff clay. Géotechnique 1997;47:953-82.

[19] Gens A, Alonso EE. Aznalcóllar dam failure. Part 2: Stability conditions and failure. Geotechnique 2006;56:185-201.

[20] Zabala F, Alonso EE. Progressive failure of Aznalcóllar dam using the material point method. Géotechnique 2011;61:795-808. doi:10.1680/geot.9.P.134.

[21] Troncone A. Numerical analysis of a landslide in soils with strain-softening behaviour. Geotechnique 2005;55:585-96.

[22] Troncone A, Conte E, Donato A. Two and three-dimensional numerical analysis of the progressive failure that occurred in an excavation-induced landslide. Eng Geol 2014;183:265-75. doi:10.1016/j.enggeo.2014.08.027.

[23] Alonso EE, Pinyol NM. Slope stability in slightly fissured claystones and marls. Landslides 2014. doi:10.1007/s10346-014-0526-5.

[24] Soga K, Alonso E, Yerro A, Kumar K, Bandara S. Trends in large-deformation analysis of landslide mass movements with particular emphasis on the material point method. Géotechnique 2015. doi:http://dx.doi.org/10.1680/jgeot.15.LM.005.

[25] Sulsky D, Zhou S-J, Schreyer HL. Application of a particle-in-cell method to solid mechanics. Comput Phys Commun 1995;87:236-52. doi:10.1016/0010-4655(94)001707.

[26] Beuth L, Wieckowski Z, Vermeer PA. Solution of quasi- $\square$ static large- $\square$ strain problems by the material point method. Int J Numer Anal Methods Geomech 2011;35:1451-65. doi:10.1002/nag.

[27] Jassim I, Stolle D, Vermeer P. Two- $\square$ phase dynamic analysis by material point method. 
Int J Numer Anal Methods Geomech 2013;37:2502-22. doi:10.1002/nag.

[28] Yerro A, Alonso E, Pinyol N. The material point method for unsaturated soils. Géotechnique 2015;65:201-17. doi:http://dx.doi.org/10.1680/geot.14.P.163.

[29] Hamad F, Stolle D, Vermeer P. Modelling ofmembranes in thematerial point method with applications. Int J Numer Anal Methods Geomech 2015;39:833-53. doi:10.1002/nag.

[30] Conte E, Silvestri F, Troncone A. Stability analysis of slopes in soils with strainsoftening behaviour. Comput Geotech 2010;37:710-22.

[31] Alonso E, Yerro A, Pinyol N. Recent developments of the Material Point Method for the simualtion of landslides. Keynote Lect. Int. Symp. Geohazards Geomech., Warwick, UK: 2015.

[32] Cooper M, Bromhead E, Petley D, Grant D. The Selborne cutting stability experiment. Geotechnique 1998;48:83-101.

[33] Sulsky D, Chen Z, Schreyer HL. A particle method for history-dependent materials. Comput Methods Appl Mech Eng 1994;118:179-96. doi:10.1016/0045-7825(94)901120 .

[34] Sulsky D, Schreyer HL. Axisymmetric form of the material point method with applications to upsetting and Taylor impact problems. Comput Methods Appl Mech Eng 1996;139:409-29. doi:10.1016/S0045-7825(96)01091-2.

[35] Abe K, Soga K, Bandara S. Material point method for coupled hydromechanical problems. J Geotech Geoenvironmental Eng 2014;140:1-16. doi:10.1061/(ASCE)GT.1943-5606.0001011.

[36] Cromer A. Stable solutions using the Euler approximation. Am J Phys 1981;49:455-9.

[37] Cundall PA. Distinct element models of rock and soil structure. In: Brown ET, editor. Anal. Conlputational Methods Eng. Rock Mech., London: Allen and Unwin; 1987, p. 129-63.

[38] Al-Kafaji IKJ. Formulation of a Dynamic Material Point Method ( MPM ) for Geomechanical Problems. Universität Stuttgart, 2013.

[39] Bardenhagen SG, Kober EM. The generalized interpolation material point method. Comput Model Eng Sci 2004;5:477-95. doi:10.3970/cmes.2004.005.477.

[40] Sadeghirad A, Brannon R, Burghardt J. A convected particle domain interpolation technique to extend applicability of the material point method for problems involving massive deformations. Int J Numer Methods Eng 2011;86:1435-56. doi:10.1002/nme.

[41] Kamojjala K, Brannon R, Sadeghirad A, Guilkey J. Verification tests in solid mechanics. Eng Comput 2013;31:193-213. doi:10.1007/s00366-013-0342-x.

[42] Abbo A, Sloan S. A smooth hyperbolic approximation to the Mohr-Coulomb yield criterion. Comput Struct 1995;54:427-41.

[43] Dounias G, Potts D, Vaughan P. Finite element analysis of progressive failure: two case studies. Comput Geotech 1988;6:155-75.

[44] Potts D, Dounias G, Vaughan P. Finite element analysis of progressive failure of Carsington embankment. Géotechnique 1990;40:79-101.

[45] Dounias G, Potts D, Vaughan P. Analysis of progressive failure and cracking in old British dams. Géotechnique 1996;46:621-40.

[46] Potts D, Zdravkovic L. Finite element analysis in geotechnical engineering: application. London: Thomas Telford; 1999.

[47] Potts D, Kovacevic N, Vaughan P. Delayed collapse of cut slopes in stiff clay. Géotechnique 1997;47:953-82. 
[48] Yerro A. MPM modelling of landslides in brittle and unsaturated soils. Universitat Politècninca de Catalunya, 2015.

[49] Rots JG, Nauta P, Kuster GMA, Blaauwendraad J. Smeared Crack Approach and Fracture Localization in Concrete. Heron 1985;30:1-48.

[50] Yerro A, Alonso E, Pinyol N. Modelling progressive failure with MPM. In: Hicks M, Brinkgreve RBJ, Rohe A, editors. Numer. Methods Geotech. Eng., 214 Taylor \& Francis Group; 2014, p. 319-23.

[51] Scheidegger AE. On the prediction of the reach and velocity of catastrophic landslides. Rock Mech 1973;5:231-6.

[52] Hsü KJ. Catastrophic debris streams generated by rockfalls. Geol Soc Am Bull 1975;86:129-40.

[53] Sassa K. Special lecture: Geotechnical model for the motion of landslides. In: Bonnard C, editor. Proc. 5th Symp. Landslides, vol. 1, Rotterdam: Balkema; 1988, p. 37-55. 